\title{
ASSOCIATION OF SOUTHEAST ASIAN NATIONS
}

ASEAN PROGRESS TOWARDS SUSTAINABLE DEVELOPMENT GOALS AND THE ROLE OF THE IMF

\section{ASEAN Leaders Gathering}

October 11, 2018

Bali, Indonesia

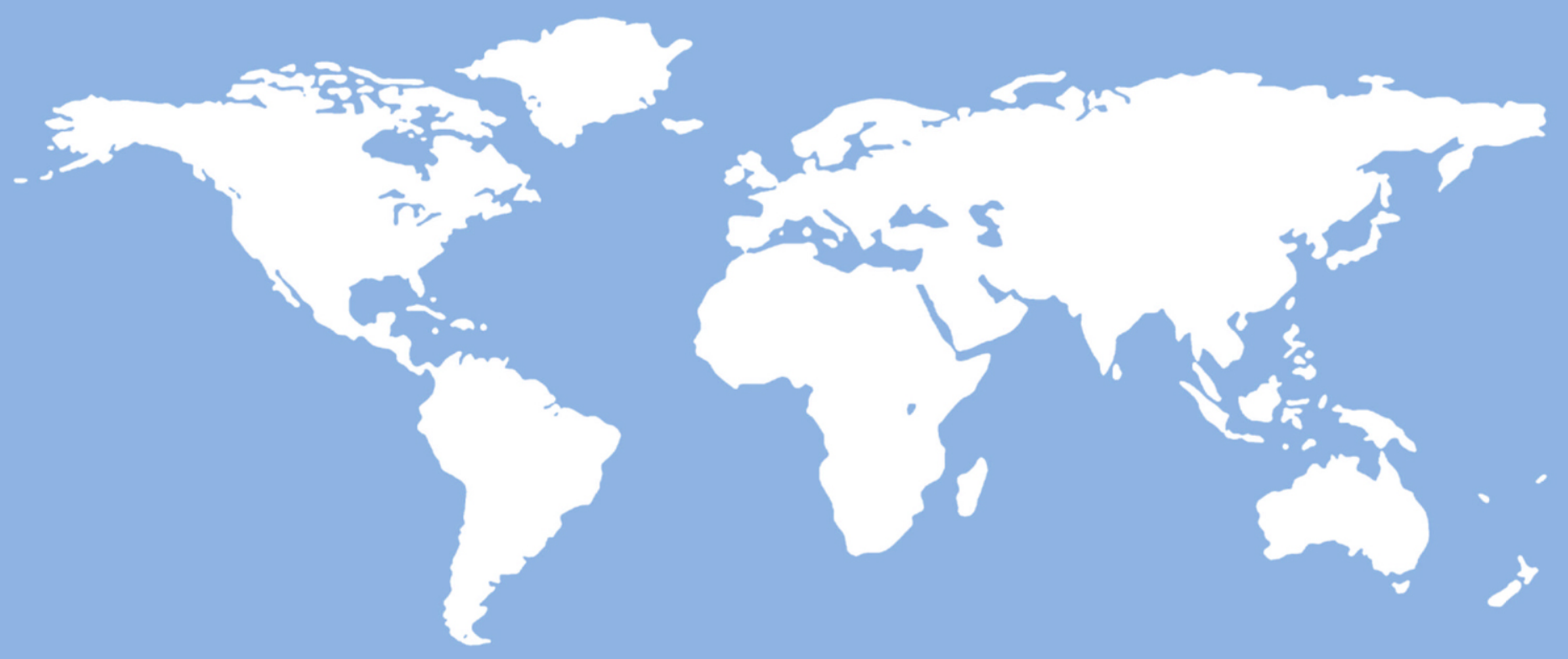

Prepared by Staff of the

I NTER NATIONAL MONETARY F U N D*

*Does not necessarily reflect the views of the IMF Executive Board. 


\section{ASSOCIATION OF SOUTHEAST ASIAN NATIONS}

ASEAN PROGRESS TOWARDS SUSTAINABLE DEVELOPMENT GoALS AND

THE ROLE OF THE IMF

\section{ASEAN Leaders Gathering \\ October 11, 2018 \\ Bali, Indonesia}

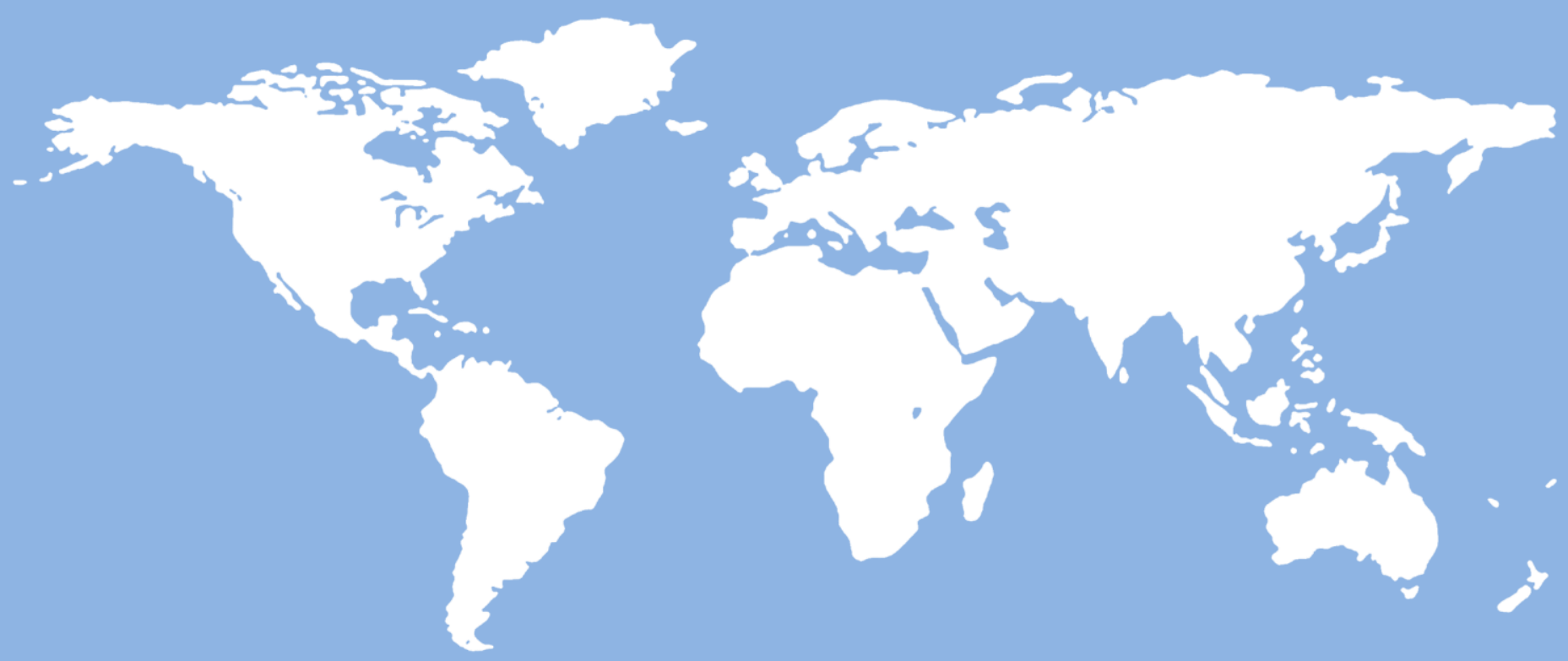

\section{Prepared by Staff of the}

I NTER N A T I O NAL MONETARY F U N D*

*Does not necessarily reflect the views of the IMF Executive Board. 


\section{INTERNATIONAL MONETARY FUND}

September 27, 2018

\section{ASEAN PROGRESS TOWARDS SUSTAINABLE DEVELOPMENT GOALS AND THE ROLE OF THE IMF}

\section{EXECUTIVE SUMMARY}

Attainment of the Sustainable Development Goals (SDGs) will require that the Association of Southeast Asian Nations (ASEAN) countries continue their considerable past achievements. The Millennium Development Goals-which were to have been met by 2015-helped focus attention on achieving progress towards poverty reduction, better health outcomes, and improvements in education in the ASEAN developing countries. The 17 SDGs-adopted in 2015 and to be met by 2030_cover a wider set of interlinked development objectives, such as inclusion and environmental sustainability, which are important for all countries, including all ASEAN member countries.

ASEAN countries have made significant progress in improving incomes and economic opportunities, including for women, and reducing poverty since 2000. Reflecting the economic dynamism of the region, strong income growth, structural transformation, and infrastructure improvements continue to support sustainable development in ASEAN. With continued income growth and strong policy efforts, most ASEAN countries are on track to eradicate absolute poverty by 2030 , a major milestone. Also, several ASEAN countries already do relatively well in terms of gender equality. As a result, given support from continued income gains, economic welfare in ASEAN countries is expected to continue converging towards advanced Asia levels.

Ensuring more inclusive and environmentally sustainable growth presents a key challenge for ASEAN. Despite some progress, income inequality remains relatively high in several countries and the shift towards manufacturing strains environmental sustainability. These challenges hamper ASEAN welfare convergence relative to advanced Asia. Policies to close these gaps in sustainable development can lead to significant gains. For the lower-middle-income ASEAN countries, in particular, more determined policy efforts are needed to improve infrastructure, as well as health and education outcomes. Remaining sustainable development challenges call for comprehensive, country-specific SDG strategies formulated in the context of national development plans and close monitoring through the voluntary review process.

Pursuing sustainable development entails sizeable spending needs. Estimates for Indonesia and Vietnam, the two cases studies considered in this paper, show that 
reaching the level of best performers in their income group in infrastructure, health, and education by 2030 could entail an additional cost of 51/2-61/2 percent of GDP per year. While development needs vary across countries, estimates suggest large spending needs for most ASEAN countries. Meeting them will require efforts on multiple fronts, including improvements in spending efficiency, tax capacity, and support from the private sector. For developing ASEAN countries, concessional financing from development partners will be required.

\section{The IMF continues to engage ASEAN countries in key areas as they pursue their}

SDGs. As called for in their mandates, ASEAN and the IMF both strive for economic growth and sustainable development through economic integration and collaboration among their member countries. The IMF has increased its engagement with ASEAN countries to support their policy efforts through its policy diagnostics, advice, and capacity development. ASEAN countries have also received support through IMF initiatives in strengthening revenue mobilization, building state capacity for infrastructure provision, pursuing economic and financial inclusion, addressing the challenges of climate change, strengthening economic institutions for good governance, and building statistical capacity. While fundamental reforms to improve sustainable development take time to bear fruit, there is evidence that efforts have started to pay off. 
Approved By Markus Rodlauer (APD), Sean Nolan (SPR), and Michael Keen (FAD)
Prepared by a staff team led by Jarkko Turunen (APD), Stefania Fabrizio (SPR), and Mercedes Garcia-Escribano (FAD) under the guidance of Nada Choueiri (APD). Team members include Calixte Ahokpossi, Geoffrey Bannister, David Corvino, Jonathan Dunn, Albe Gjonbalaj, Yiqun Wu and Yun He (APD); Daniel Gurara and Etienne Yehoue (SPR); and Anja Baum, Emine Hanedar, Hui Jin, Delphine Prady, and Mauricio Soto (FAD).

\section{CONTENTS}

Abbreviations and Acronyms

INTRODUCTION

ASEAN PROGRESS TOWARDS SUSTAINABLE DEVELOPMENT $\underline{8}$

A. Selected SDG Indicators

B. SDGs and Welfare $\underline{13}$

ASEAN SPENDING NEEDS FOR EDUCATION, HEALTH AND INFRASTRUCTURE 18

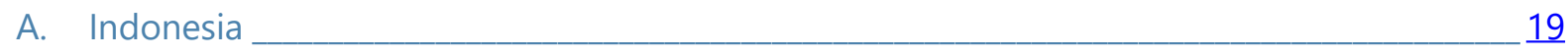

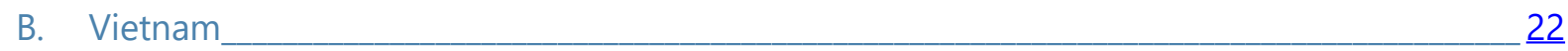

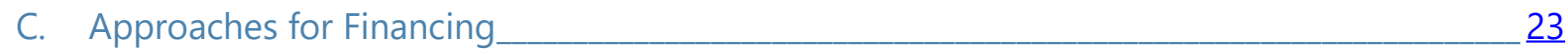

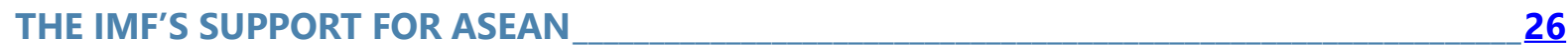

A. Strengthening Resource Potential _______ 27

B. Building State Capacity for Infrastructure Provision_____ 29

C. Pursuing Economic and Financial Inclusion __________

D. Addressing the Challenges of Climate Change______ 32

E. Strengthening Institutions for Good Governance _________ 33

CONCLUSIONS _____________________________________

References_____ $\underline{35}$

\section{BOXES}

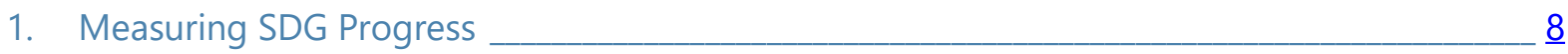

2. SDGs in National Development Plans_______ 17

3. Fiscal Policy Goes Digital in ASEAN Countries_______

\section{FIGURES}

1. Sustainable Development Goals ______ $\underline{6}$

2. ASEAN Countries' GDP Per Capita and Poverty Rate__________

3. Selected Indicators of Poverty, Health, and Education _____ 10 
4. Selected Indicators of Inclusion_______

5. Income and Welfare Convergence_________________________________________

6. Components of Welfare ____ 15

7. Welfare Convergence in an Active Scenario_______

8. Indonesia and Vietnam: Total and Public Additional Spending Needs____ 21

9. The IMF's Capacity Development Priorities and the SDGs_____ 27

10. Tax Revenue to GDP in Emerging and Developing Asia_______ 27

11. Tax Revenue Developments in Selected ASEAN Countries, 2010-2017______ 28

12. ASEAN Infrastructure Investment Gap _____ 29

13. Number of Financial Sector TAs Since 2015______ 32

\section{TABLE}

1. Benchmarking Education Needs

\section{APPENDICES}

I. Progress Towards MDGs_____

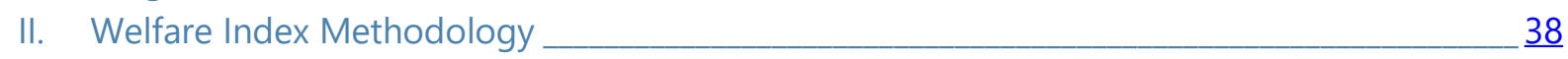

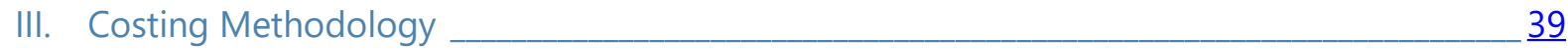

IV. IMF's New Initiatives Under the 2030 Development Agenda______ 41 


\section{Abbreviations and Acronyms}

$\begin{array}{ll}\text { AMRO } & \text { ASEAN +3 Macroeconomic Research Office } \\ \text { CDOT } & \text { Capacity Development Office in Thailand } \\ \text { CO2 } & \text { Carbon dioxide } \\ \text { DIG } & \text { Debt-Investment-Growth Model } \\ \text { DIGNAR } & \text { Debt, Investment, Growth, and Natural Resources Model } \\ \text { DSA } & \text { Debt Sustainability Analysis } \\ \text { FAS } & \text { Financial Access Survey } \\ \text { FfD } & \text { Financing for Development } \\ \text { FSIs } & \text { Financial Soundness Indicators } \\ \text { FSSR } & \text { Financial Sector Stability Review } \\ \text { ICD } & \text { Institute for Capacity Development } \\ \text { IPSI } & \text { Infrastructure Policy Support Initiative } \\ \text { MDGs } & \text { Millennium Development Goals } \\ \text { MTDS } & \text { Medium-Term Debt Management Strategy } \\ \text { MTRS } & \text { Medium-Term Revenue Strategy } \\ \text { NAP } & \text { National Action Plan } \\ \text { P-FRAM } & \text { Public-Private Partnerships Fiscal Risk Assessment Model } \\ \text { PIMA } & \text { Public Investment Management Assessment } \\ \text { PISA } & \text { Programme for International Student Assessment } \\ \text { PPP } & \text { Public Private Partnerships } \\ \text { SDGs } & \text { Sustainable Development Goals } \\ \text { SDSN } & \text { Sustainable Development Solutions Network } \\ \text { SEZ } & \text { Special Economic Zone } \\ \text { STI } & \text { Singapore Regional Training Institute } \\ \text { TA } & \text { Technical Assistance } \\ \text { VAT } & \text { Value-added-tax } \\ \text { VNR } & \text { World Economic Outlook } \\ \text { WEO } & \end{array}$




\section{INTRODUCTION}

\section{ASEAN developing countries made significant progress towards meeting the}

Millennium Development Goals (MDGs). The MDGs provided an important set of targets for securing progress towards poverty reduction, which has been impressive, and better health and education outcomes. For example, by 2015, the goal year for the MDGs, absolute poverty declined to between 2 and 17 percent in four lower-middle-income ASEAN countries, while the child mortality rate declined to between 22 and 66 (per 1,000) and most countries achieved universal primary education completion (Appendix I). However, ASEAN developing countries made less headway in other areas of sustainable development. For example, ASEAN's own assessment of the MDGs noted that progress in achieving sustainable development was mixed and identified inclusive economic and social progress and climate change among new and emerging challenges for the region (UNDP and ASEAN Secretariat 2015).

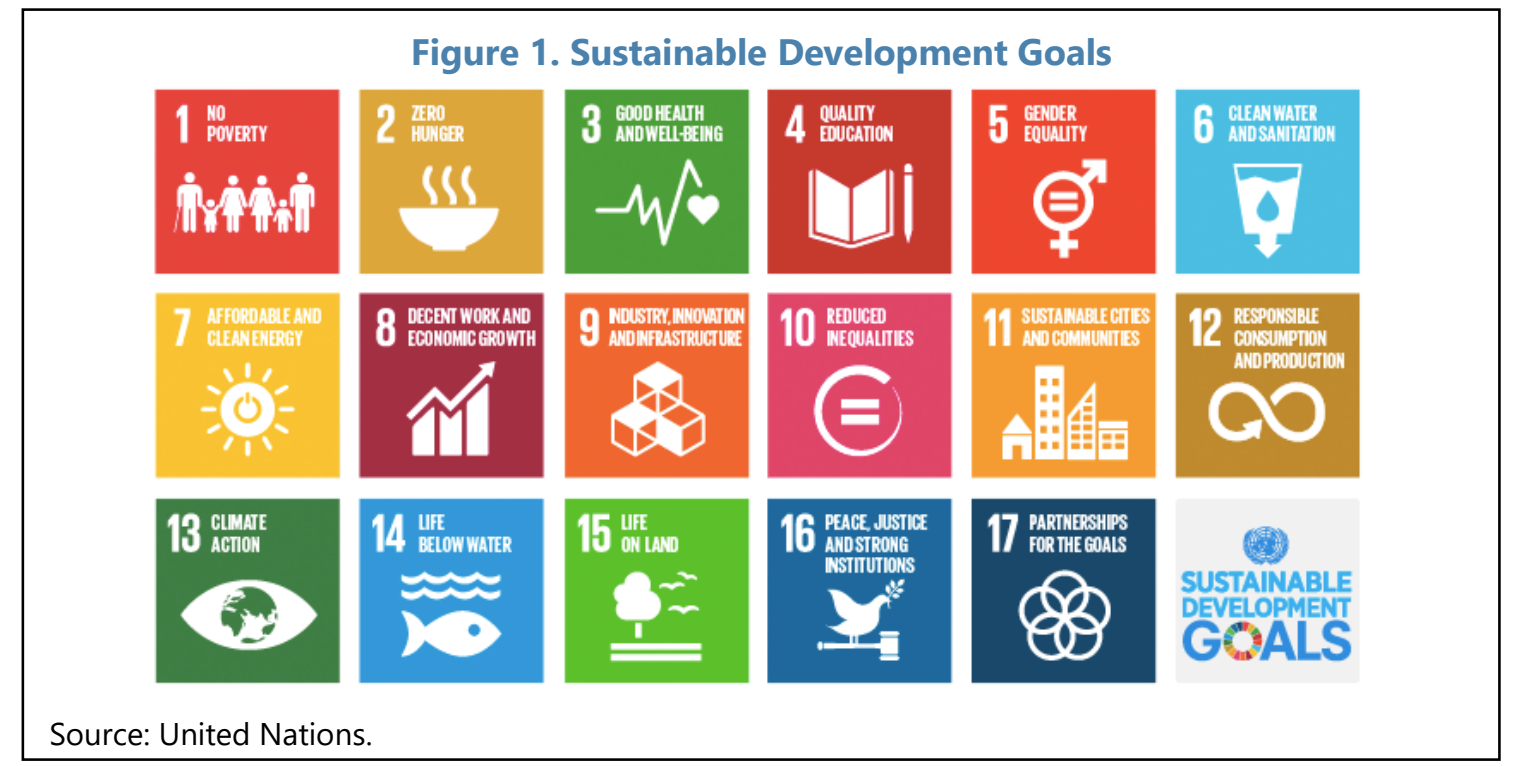

2. The SDGs represent a significant broadening of the specifications as to what constitutes sustainable development. The 17 SDGs cover a broader set of development outcomes than the earlier MDGs, embracing the view that development needs to be economically, socially, and environmentally sustainable (Figure 1). ${ }^{1}$ While the MDGs only covered developing countries, in September 2015, the SDGs were endorsed by all UN member states, including all ASEAN countries.
Figure 2. ASEAN Countries' GDP per capita and Poverty Rate

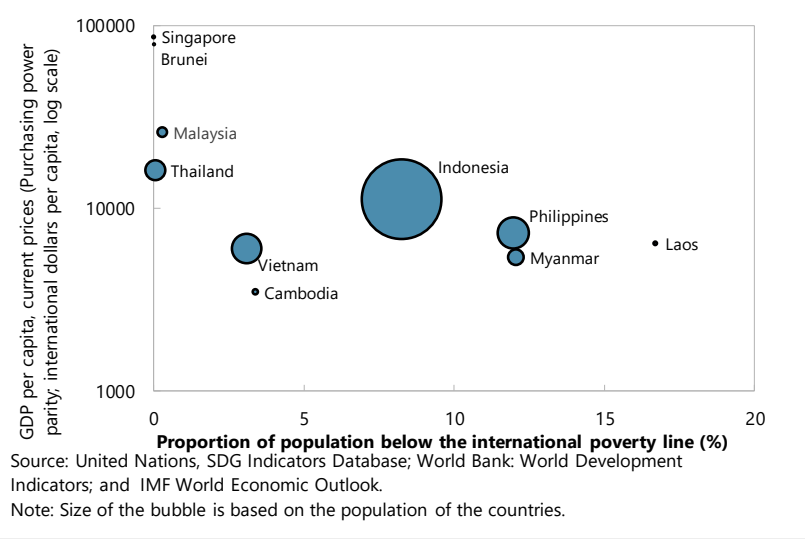

\footnotetext{
${ }^{1}$ https://sustainabledevelopment.un.org/hlpf.
} 


\section{Reflecting the diversity of the region, ASEAN countries face different challenges in} pursuing their sustainable development agenda. ASEAN countries are diverse, with GDP per capita ranging from about $\$ 1,390$ in Cambodia, a lower-middle-income developing economy, to $\$ 57$, 713 in Singapore, a high-income advanced economy (World Economic Outlook 2018). ${ }^{2}$ Most ASEAN members are middle-income countries, but even that group is diverse in terms of size and sustainable development outcomes, with absolute poverty rates, for example, ranging from zero to more than 15 percent (Figure 2). Many ASEAN countries need to reorient their policies to improve the quality of (relatively high) income growth, including to make sure that it is environmentally sustainable and that the benefits are broadly shared across the population. For the lower-middleincome ASEAN countries, in particular, development needs are larger, calling for policies to further improve health and education outcomes and address infrastructure gaps. Addressing these and other sustainable development challenges calls for country-specific policies, in the context of national development plans. Such policies entail significant spending needs, which are likely to vary across ASEAN countries, and strengthening state capacity in most cases.

\section{The IMF, with its mandate to promote economic growth and stability, is well} positioned to support ASEAN countries as they pursue their SDGs. With its macroeconomic focus and global membership, the IMF works directly with its member countries to help ensure a supportive and enabling environment for sustainable development (Annett and Lane 2018). In line with its mandate, the IMF committed in 2015 to new initiatives to support developing countries in their efforts to achieve inclusive economic growth and lasting economic development. ${ }^{3}$ Specifically, the new initiatives aim to enhance support, including through capacity development, for developing countries in (1) strengthening their revenue mobilization capacity; (2) ensuring that resource flows are used effectively_-particularly when addressing large infrastructure gaps without imperiling public debt sustainability; (3) intensifying policy engagement on issues related to inclusion and environmental sustainability; and (4) providing more effective support to fragile and post-conflict states. More recently, the IMF has adopted a framework to enhance its engagement in helping countries strengthen economic institutions and improve governance. In addition, the IMF is actively contributing to the framework for SDG indicators and supporting national statistics agencies.

\section{This paper evaluates ASEAN progress towards sustainable development, discusses} potential spending needs, and identifies the vehicles through which the IMF can help support

this development agenda. Section II explores the challenges faced by ASEAN by assessing member countries' progress toward achieving the SDGs. The section uses a summary indicator to provide an understanding of the SDGs' contribution to improving economic welfare. The results point to several bright spots for the ASEAN, but also suggest that country-specific policies are needed to improve sustainable development outcomes. Section III discusses additional financing needs to achieve the SDGs. Specifically, it provides an illustrative analysis of additional spending needs in three priority areas (health, education, and infrastructure) using two country case studies (Indonesia and Vietnam).

\footnotetext{
${ }^{2}$ ASEAN countries are Brunei, Cambodia, Indonesia, Lao PDR, Malaysia, Myanmar, Philippines, Singapore, Thailand, and Vietnam. ASEAN lower-middle-income countries include Cambodia, Indonesia, Lao PDR, Myanmar, Philippines, and Vietnam (based on the World Bank definition).

3 The new commitments made by the IMF to support the 2030 Development Agenda are outlined in IMF (2015a, 2015b, and 2015c).
} 
Section IV takes stock of recent IMF initiatives and documents significant engagement with ASEAN countries as they pursue their SDGs. Section $V$ concludes.

\section{ASEAN PROGRESS TOWARDS SUSTAINABLE DEVELOPMENT}

6. This section measures progress towards sustainable development and its welfare implications. Measuring progress is challenging for several reasons. In this paper, analysis of progress towards SDGs is based on a broad set of selected indicators with focus on areas that are closely related to the work of the IMF including poverty, health and education, inclusion, and environmental sustainability (Box 1). This is complemented by an analysis of the welfare implications of progress towards SDGs, based on recent research on measuring economic welfare (Jones and Klenow 2016 and Bannister and Mourmouras 2017).

\section{Box 1. Measuring SDG Progress}

Measuring progress toward Sustainable Development Goals (SDGs) is challenging. The broad framework, limited availability of comparable and timely data, and lack of quantitative targets for many SDG indicators pose a challenge for measuring progress. ${ }^{1 /}$ Researchers and policymakers have thus far used two approaches. The "dashboard" approach is based on analyzing changes in selected indicators for each SDG. ${ }^{2 /}$ Alternatively, the Sustainable Development Solutions Network and the Bertelsmann Stiftung (2018) have developed an SDG index that combines a large set of individual indicators where each indicator is normalized and weighted equally. ${ }^{3 /}$ The SDG index has its advantages, including the use of a large set of information, and is used in Section III to benchmark the current level of health and education outcomes against comparators. However, as of now, no time series information is available for the SDG index, making it difficult to measure progress.

We use selected sustainable development indicators and build projections to assess progress up to 2030 based on past trends. The selected indicators cover the SDG areas that are closely related to the work of the IMF, including economic opportunities and poverty as well as emerging issues in IMF policy analysis and advice such as health and education, inclusion, and environmental sustainability. Within these broad areas, the selection of tracked indicators is guided by parsimony (to keep the analysis tractable) and data quality and availability for Association of Southeast Asian Nations member countries. ${ }^{4 /}$ To analyze potential progress based on current policies, this paper uses macroeconomic projections from the Spring 2018 World Economic Outlook dataset and linear extrapolations of past trends in the selected SDG indicators to build illustrative scenarios of progress up to 2030 (for a similar approach, see ODI 2016). ${ }^{5 /}$ Progress is benchmarked against an advanced Asia aggregate (Japan, Australia, and Korea).

1/ The IMF provides its expertise and four databases for monitoring the SDGs: (1) the Financial Access Survey to measure financial inclusion; (2) the Financial Soundness Indicator database to provide measures for financial sector stability; (3) The World Revenue Longitudinal Dataset to measure government revenue-to-GDP; and (4) the Government Finance Statistics database to measure the share of domestic budget funded by domestic taxes.

2/ See, for example, http://datatopics.worldbank.org/sdgs/ and https://unstats.un.org/sdgs/report/2018/overview. 3/ Sustainable Development Solutions Network (SDSN) and the Bertelsmann Stiftung (2018): "2018 SDG Index and Dashboards Report," available at: http://www.sdgindex.org/. See also Schmidt-Traub and others 2017 and OECD 2017. 4/ For each area, the focus is on indicators for which there is sufficient data for most ASEAN countries, that is, (1) there is an observation in (or around) 2015 for at least seven out 10 countries, and (2) there are at least four data points since 2005 (with a few exceptions), to derive the historical trend. Historical trend for each indicator is approximated with the average annual growth rate between the first and last observations.

5/ The simple linear extrapolation of past trends does not account for factors such as changes in demographic trends or nonlinearities (for example, there is evidence that poverty reduction becomes more difficult when absolute poverty approaches zero). 


\section{A. Selected SDG Indicators}

7. Maintaining past good performance would help achieve significant declines in poverty and improvements in health and education outcomes. If ASEAN countries were to maintain their past performance, the region would make important progress in eradicating absolute poverty (Figure 3). However, despite past progress, some ASEAN lower-middle-income countries, still face significant challenges in improving health and education outcomes.

- $\quad$ Poverty. The proportion of the population living below the international poverty line (absolute poverty) is currently about 3 percent in the median ASEAN country, albeit higher (at about 10 percent) for the median lower-middle-income ASEAN country. The same is true for other dimensions of poverty (including relative poverty based on national poverty lines). At current trends, absolute poverty would decline substantially and is expected to be nearly eradicated in most ASEAN countries by 2030. Outcomes are expected to improve the most in countries with the highest starting levels, while poverty reduction is likely to become more challenging as absolute poverty gets closer to zero.

- Education. Many ASEAN countries perform well in terms of education outcomes. Nevertheless, with a 78 percent enrollment rate in lower secondary school and a ratio of 18 pupils to teacher for the median ASEAN country, the region trails advanced Asia. At current trends, enrollment would rise moderately and the pupil-to-teacher ratio would decline, with the lower-middle-income ASEAN catching up with the overall ASEAN median by 2030.

- Health. Basic health indicators generally show substantial gaps relative to advanced Asia, albeit with some encouraging bright spots. For the median ASEAN country, mortality for children under the age of five amounts to 24.5 per 1,000 live births, already below the global SDG (at 25 per 1,000 live births). ${ }^{4}$ As expected, health outcomes are poorer for lower-middleincome ASEAN countries. For example, maternal mortality remains relatively high at 143.5 maternal deaths per 100,000 live births (compared to the global SDG of 70 per 100,000 live births. If recent positive trends continue, health outcomes measured by these indicators are projected to improve significantly. However, the life expectancy gap between the median ASEAN country and advanced Asia remains substantial and is projected to persist through 2030. This suggests that significant gaps remain in other dimensions of health that are not captured by the indicators analyzed here.

\footnotetext{
${ }^{4}$ https://sustainabledevelopment.un.org/sdgs.
} 
Figure 3. Selected Indicators of Poverty, Health, and Education
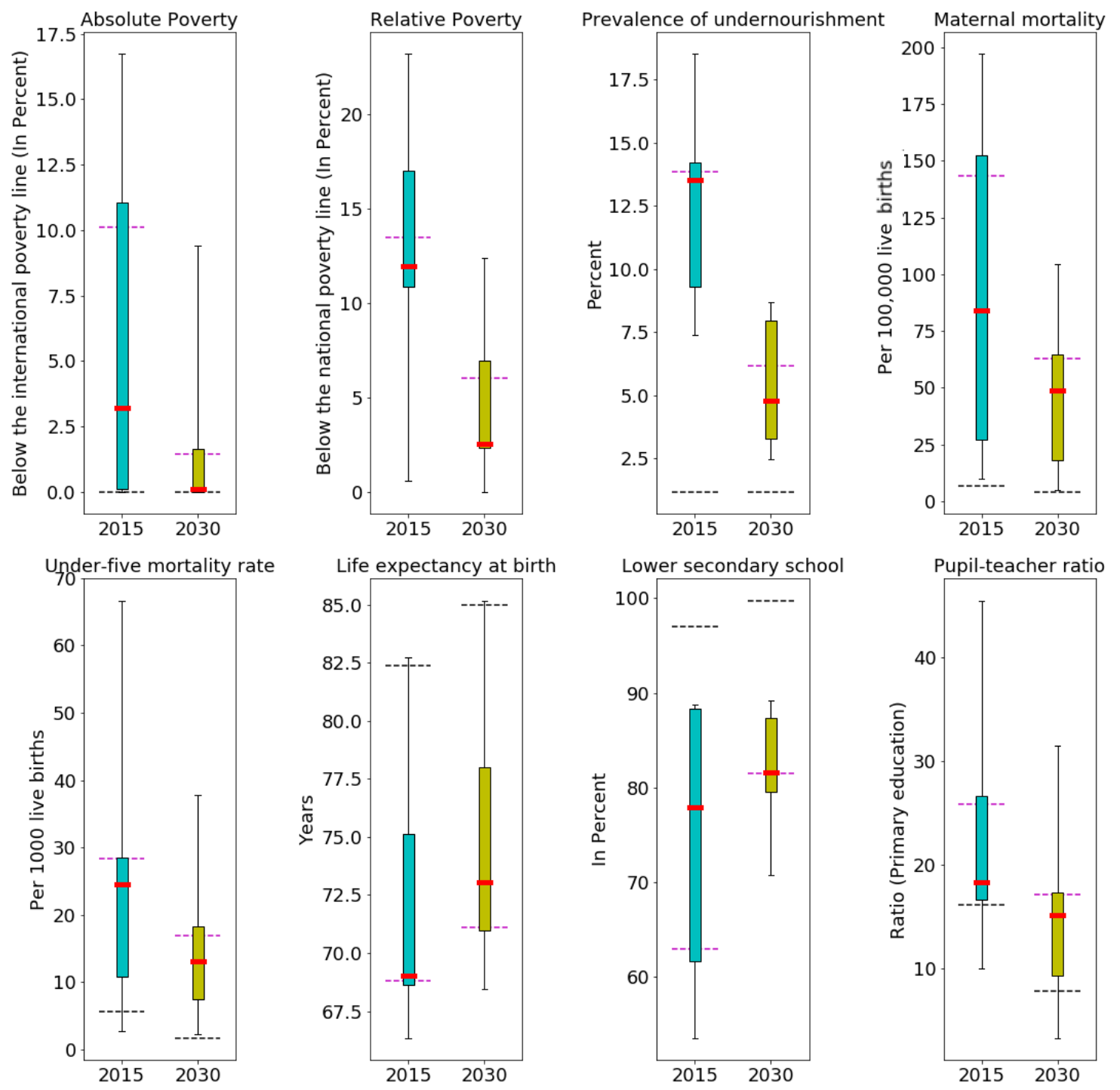

Source: United Nations; IMF staff estimates.

Note: The red line represents the ASEAN median; the box and vertical lines represent the interquartile range, minimum, and maximum; the dark dotted line represents the advanced Asia median; and the pink dotted line represents the lower-middle-income ASEAN country median. Absolute poverty is measured by the international poverty line ( $\$ 1.90$ dollars in purchasing power parity terms).

8. Strong income growth and structural transformation have broadened economic opportunities, including for females, but improving inclusion remains a key challenge. The region has benefited from an environment that has generally supported structural transformation towards more diversified economies. For example, while currently lagging advanced Asia, manufacturing employment has increased and, under current trends, the ASEAN median is projected to exceed the advanced Asia median by 2030 (Figure 4). Unemployment is also low in ASEAN relative 
to advanced Asia. However, youth unemployment is much higher in ASEAN, particularly in lowermiddle-income ASEAN countries (11 percent for the median), suggesting that some countries in the region are struggling to provide economic opportunities for their youth.

- Infrastructure. Reflecting growth and past investment in infrastructure, access to electricity for the general population is one the best achievements in ASEAN countries. Most ASEAN countries currently have electricity penetration above 97 percent and past trends suggest that by 2030, only one country in the region is expected to have less than full electricity penetration. Nevertheless, broader infrastructure gaps remain in several lower-middleincome ASEAN countries. ${ }^{5}$

- $\quad$ Gender. While there is still need for further progress, ASEAN countries compare favorably to advanced Asia in terms of gender equality. Female representation in managerial positions is relatively high (at 30 percent for the median). On the political front, progress in female inclusion is also strong, though uneven across countries in the region. The proportion of women in parliament, at close to 20 percent in the median ASEAN country, is higher than the share in advanced Asia (13 percent). Furthermore, this is an area where lower-middle-income countries do at least as well as the median ASEAN country.

- Inequality. While there has been some progress in the past, income inequality (as measured in this study by the Gini coefficient) is higher in ASEAN (about 38 for the median) than in advanced Asia (32). The relatively high levels of income inequality compared to advanced Asia are broadly shared across ASEAN countries. Other indirect indicators of inequality, such as the proportion of the population living in slums, informal settlements, or inadequate housing, are also high. Looking forward, there is large variation in trends in income inequality, which for the ASEAN median country translates into no expected improvement in income inequality up to 2030, while quality of housing is projected to improve gradually based on past trends.

${ }^{5}$ Infrastructure needs are largest in power and transportation, followed by telecommunications, and to a lesser extent water and sanitation (ADB 2017). 


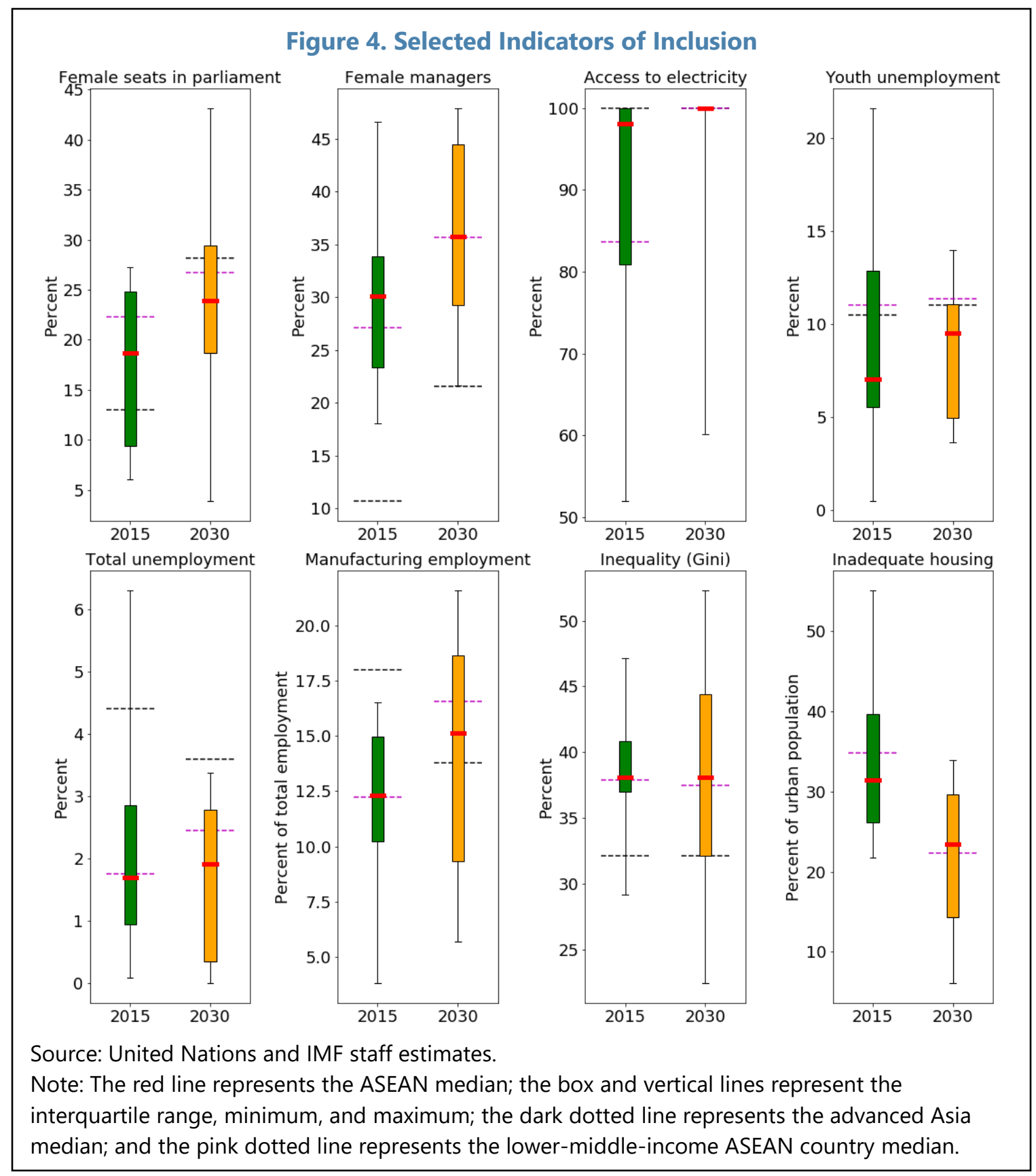

9. Higher incomes and the shift towards manufacturing in some ASEAN countries strain environmental sustainability. Carbon dioxide emissions per capita is currently lower in all ASEAN countries than in advanced Asia. However, despite commitments under the Paris Agreement, some countries in the region are expected to significantly increase their carbon dioxide emissions as they continue to grow and increasingly industrialize over the next decade. This is in line with the projected increase of the share of manufacturing employment as a proportion of total employment (see above). In addition to carbon emissions, ASEAN countries face other challenges in achieving environmentally sustainable growth. For example, air pollution levels are increasing, economic losses from natural disasters are on the rise, and deforestation is contributing to concerns about climate change mitigation and leading to land erosion (ASEAN 2017). 


\section{B. SDGs and Welfare}

\section{Benefits of progress towards SDGs can be illustrated using a summary indicator of} economic welfare. The welfare index developed by Jones and Klenow (2016), a widely recognized summary indicator of economic well-being, and extended by Bannister and Mourmouras (2017) provides a methodology for estimating the economic benefits of making progress towards SDGs. ${ }^{6}$ Components of the welfare index are closely linked to a subset of the SDGs. Specifically, the indicators included in the analysis, and the corresponding SDGs, are: (1) income per capita and ratio of consumption to income (SDGs 1, 2, and 8), (2) life expectancy at birth (SDG 3), (3) inequality as measured by the Gini coefficient (SDG 10), and (4) the cost of greenhouse gas emissions (SDG 13) (see Appendix II for more details on the welfare index methodology). Similar to the approach based on selected indicators above, the welfare index is projected up to 2030 using a scenario based on past trends for the underlying indicators and benchmarked against an advanced Asia aggregate. Potential gains that would stem from additional policy efforts to improve sustainable development are illustrated using an active scenario.

\section{ASEAN countries benefit from welfare convergence supported by gains in income,} consumption, and higher life expectancy. The welfare index shows that, reflecting strong and sustained economic growth, ASEAN countries have experienced significant income convergence over the past decade (Bannister and Mourmouras 2017). Income per capita in the median ASEAN country has reached about 20 percent of the advanced Asia level (Figure 5 ). ${ }^{7}$ The distribution across ASEAN countries shows large variation, with Singapore, a high-income country, exceeding advanced Asia levels in income per capita, with several lower-middle-income ASEAN countries trailing well behind. ${ }^{8}$ A scenario based on past trends and WEO projections shows that ASEAN countries are likely to see further income convergence, with income per capita in the median ASEAN country growing to around 35 percent of the advanced Asia level by 2030. Moreover, expected rebalancing of ASEAN countries towards higher consumption would impact individuals towards the bottom of the income distribution, thus supporting further reductions in poverty over time. The relative income gains would be larger for lower-middle-income ASEAN countries, thus supporting convergence within the ASEAN and poverty reduction. Finally, life expectancy, a broad measure of health outcomes, is expected to improve, thus helping to close the gap between welfare in the ASEAN countries and advanced Asia (Figure 6).

\footnotetext{
${ }^{6}$ Other summary measures that capture differences in dimensions of welfare across countries include, for example the SDG index (Sustainable Development Solutions Network and the Bertelsmann Stiftung, 2018) and the Human Development Index (UNDP 2009). However, these measures lack theoretical foundations. The Jones and Klenow (2016) welfare index is derived from a consistent theoretical model that attempts to capture the way each of the components affect consumption-equivalent welfare, that is, it assumes that welfare is proportional to the amount of consumption per capita that an economy can achieve or provide its citizens. The benefit of this approach is that it is a theoretically consistent way of looking at dimensions of economic welfare that are not captured by GDP per capita or other measures of economic success. The cost of this approach is that it only encompasses a limited number of development indicators, concentrating on the economic dimensions, and not covering other dimensions such as quality of life, peace and justice, gender equity, and environmental quality that are included in the SDGs.
}

${ }^{7}$ About 28 percent using a population weighted average for ASEAN.

${ }^{8}$ Data to compute the welfare index are not available for Brunei (the other high-income ASEAN country). 


\section{ASEAN welfare convergence is moderated by challenges in achieving other sustainable} development outcomes. Despite strong income convergence, past ASEAN improvements in welfare, as measured by the welfare index, have been broadly on par with the global average (Bannister and Mourmouras 2017). As a result, the welfare index suggests that ASEAN welfare (at about 12 percent for the median ASEAN country) remains well below the advanced Asia level (Figure 5). ${ }^{9}$ At the same time, there is wide variation across ASEAN countries, with lower-middle-income ASEAN countries generally facing more significant challenges in achieving sustainable development outcomes. ASEAN countries will benefit from a broad-based improvement, with the welfare index suggesting an improvement to about 20 percent of the advanced Asia level by 2030 . For the median ASEAN country, improvements in income, consumption, and health outcomes are weighed down by challenges related to environmental sustainability and inclusion (Figure 6). While environmental sustainability is expected to improve in several ASEAN countries, for the median ASEAN country, the cost of greenhouse gas emissions increases. Similarly, there is large variation in trends in income inequality.

Figure 5. Income and Welfare Convergence
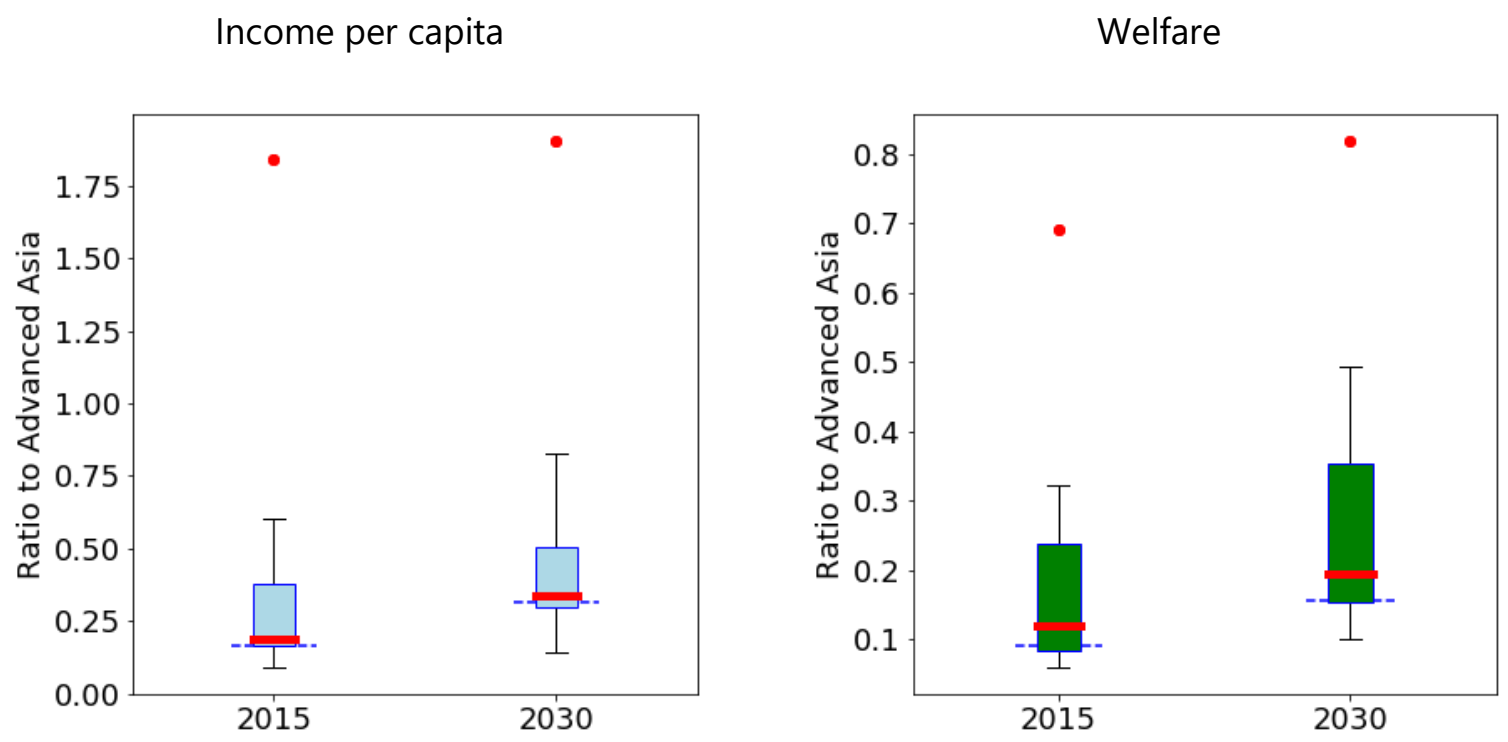

Source: PWT 9.0; WDI; UN Population Division; World Resources Institute (CAIT) and IMF staff estimates. Note: Income per capita and welfare are expressed as a share of the advanced Asia level. The red line represents the median; the box and vertical lines represent the interquartile range, minimum and maximum; and the blue dotted line represents the median for ASEAN lower-middle-income countries. The outlier (red dot) in the sample is set at the 95th percentile of the data and represents Singapore.

${ }^{9}$ About 15 percent using a population weighted average for the ASEAN. 


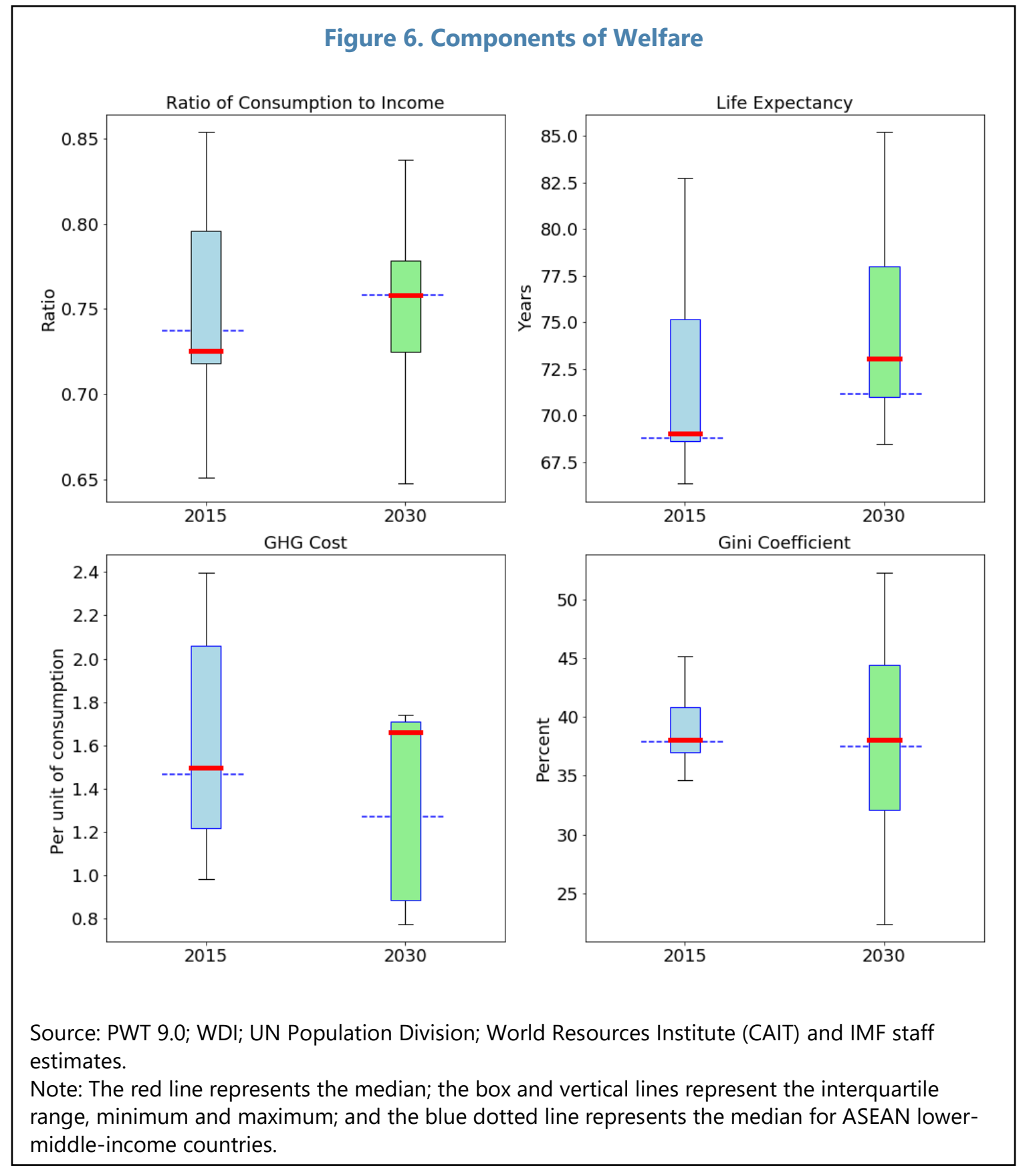

13. Reforms can lead to significant gains in welfare convergence. An active scenario based on the welfare index can be used to illustrate potential gains from closing remaining gaps in sustainable development. ${ }^{10}$ While the scenario is illustrative and does not account for countryspecific priorities, it shows that realistic improvements in sustainable development have the potential to significantly improve welfare. Specifically, the scenario shows that by 2030 the median ASEAN

10 In particular, we specify 2030 target levels of the underlying indicators based on: (1) countries' commitments under development plans or treaties (for example under the Paris Climate Agreement), or (2) the level of the indicator that is achieved in 2015 by the best performer in the next highest income category for each country (for example, a lowermiddle-income ASEAN country would aspire to reach the life expectancy level of the best-performing upper-middleincome Asian country). 
country would see a 9 percentage point improvement in welfare, bringing it close to 30 percent of the advanced Asia level (Figure 7). The projected improvement is driven by a higher share of consumption in income, higher life expectancy, lower greenhouse gas emissions, and lower income inequality.

14. Remaining sustainable development challenges call for comprehensive country-specific policies formulated in the context of national development plans. Analysis of progress shows common challenges across the ASEAN countries, which, in line with the broad SDG framework call for a comprehensive policy agenda. As shown in the active scenario, effective policies that lead to improvements in environmental sustainability, inclusion, and health outcomes can contribute to sizeable improvements in economic welfare. For example, policies to improve environmental sustainability could include reducing energy subsidies, as well as potential tax policy measures such as introducing carbon taxation (thus also contributing to higher revenues). Examples of policies that can help reduce income inequality include increasing reliance on progressive direct taxes and increases in targeted social spending to improve safety nets. Finally, for many of the ASEAN lower-middle-income countries, further improving health and education outcomes calls for higher spending in these priority areas, continued improvements in revenue mobilization, and additional efficient fiscal expenditure. However, variation across ASEAN countries also highlights that the policy agendas need to be country-specific. In this context, ASEAN countries are in the process of incorporating SDG priorities in their national development plans (Box 2). Country-specific development plans also need to account for the financing needs associated with policies to improve sustainable development.

\section{Figure 7. Welfare Convergence in an Active Scenario}

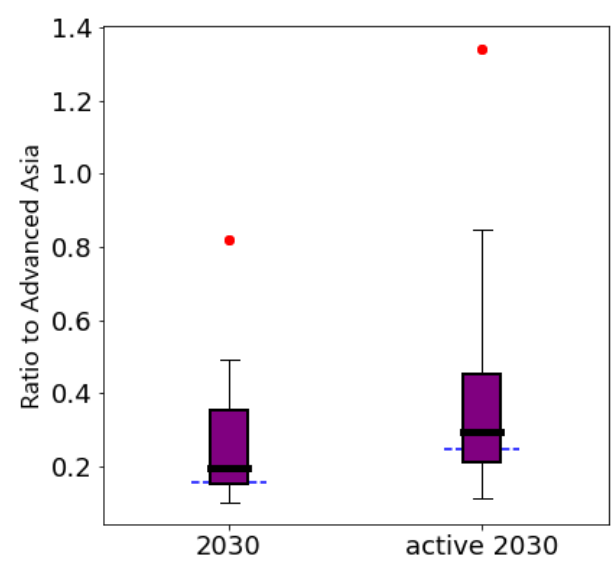

Source: PWT 9.0; WDI; UN Population Division; World Resources Institute (CAIT) and IMF staff estimates. Note: Welfare is expressed as a share of the advanced Asia level. The black line represents the median; the box and vertical lines represent the interquartile range, minimum and maximum; and the blue dotted line represents the median for ASEAN lower-middle-income countries. The outlier (red dot) in the sample is set at the 95th percentile of the data and represents Singapore. 


\section{Box 2. SDGs in National Development Plans}

Association of Southeast Asian Nations (ASEAN) member countries have committed to incorporating the Sustainable Development Goals (SDGs) in their national development plans. ASEAN countries' existing medium-term national and sectoral development plans generally do not yet explicitly and fully integrate the SDGs, though many have now mapped policies and actions in their plans to the SDGs. Moreover, all ASEAN countries have committed to design policies to pursue sustainable development.

Seven ASEAN countries have completed Voluntary National Reviews (VNRs). Indonesia, Lao PDR, Malaysia, Philippines, Singapore, Thailand, and Vietnam have completed VNRs of their progress on the SDGs. These VNR reports-presented at the UN High-Level Political Forum for Sustainable Development-also summarize the linkages between the SDGs and these countries' existing national development priorities and plans. ${ }^{1 /}$ Most of these countries have also created a national-level coordinating body on the SDGs with broad stakeholder participation (academics, civil society, government, private sector) to ensure that the goals are reflected in ongoing government work plans and annual budgets and to develop roadmaps for SDG implementation. Some of these countries have benchmarked their current national development plans against the SDGs and identified areas fully covered, gaps, and risks in their development and sectoral plans with respect to SDG implementation. Finally, most of those ASEAN countries with formal national and sectoral development plans have committed to incorporate the SDGs explicitly in these plans in the future. ${ }^{2 /}$

Completed VNRs highlight areas in which progress is being made and where some gaps exist. Consistent with the empirical results in this paper, broadly speaking, ASEAN countries are making good progress in reducing poverty (SDG1) and hunger (SDG2); improving access to, and outcomes in, health, education, sanitation, and electricity (SDGs 3, 4, 6, and 7); and fostering strong economic growth and job creation (SDG8). Some higher-income ASEAN states have made significant progress in moving toward sustainable communities, consumption, production, and climate adaptation (SDGs 11, 12, and 13). Many countries in ASEAN also exhibit good progress in certain dimensions of gender equality (SDG 5) - such as labor force participation rates, enrollment in and the quality of education for girls and women, and falling or very low maternal and child mortality rates - while some face challenges with gender balance in senior positions across the public and private sectors and/or the prevalence of high female labor force participation in the informal sector. Finally, ASEAN members, with few exceptions, exhibit widening, or high and stagnant, inequality (SDG 10) in conjunction with their impressive growth performance.

Some ASEAN countries have developed monitoring and evaluation plans for SDG implementation to complement their national development plans. Lao PDR's monitoring and evaluation framework is based on SDG indicators wherever possible and specifies detailed guidelines and possible data sources for localizing and monitoring the SDGs. ${ }^{3 /}$ This framework is helping Lao P.D.R. consider how best to fully integrate the SDGs in its future national development plans. Vietnam finalized in 2017 its National Action Plan for the implementation of the 2030 Sustainable Development Agenda. The plan lays out the key steps Vietnam will take up to 2020—when it formulates its next national development plan - to lay the institutional groundwork for SDG implementation. It also specifies detailed targets to achieve the SDGs by 2030, with explicit links to government policies, responsible ministries and agencies, and other parties who can contribute to SDG implementation.

ASEAN countries can take steps to strengthen cooperation for SDG implementation. There is currently no formal ASEAN-wide effort on SDG implementation. As mentioned in several ASEAN VNRs, and in the spirit of SDG 17 (Partnerships to Achieve the Goals), ASEAN countries may want to formalize cooperation in designing ways to achieve the SDGs. More specifically, given the challenges many 


\section{Box 2. SDGs in National Development Plans (concluded)}

countries are facing in localizing the SDGs, and then generating and analyzing data to use to monitor SDG implementation, cooperation on SDG-related data, monitoring, and evaluation issues may be helpful. Cooperation could also extend to sharing experiences in developing detailed national action plans for SDG implementation so that the SDGs can more easily be fully integrated into countries' future national development plans. In addition, Lao PDR's efforts to link indicators in its national development plan to the SDGs provides an example for the region of how to use the SDGs to help prioritize national development goals, ensure that those goals are met in a measurable way, and, ultimately, drive budget programs and allocations to meet priority goals.

1/ https://sustainabledevelopment.un.org/hlpf.

2/ Brunei (2018), Cambodia (2019) and Myanmar (first national sustainable development plan) are now preparing their next development plans.

3/ Lao P.D.R. is the only country in the world to have adopted an $18^{\text {th }}$ SDG: Lives Safe from UXO. This SDG commits to meet the challenges faced by its population from unexploded ordnance. Lao P.D.R. is the most heavily bombed country per capita in history due to the conflict in Indochina during the 1960s and 1970s.

\section{ASEAN SPENDING NEEDS FOR EDUCATION, HEALTH AND INFRASTRUCTURE}

15. This section focuses on the additional spending required for a selection of SDGs related to investments in human capital and physical infrastructure. Education, health and infrastructure, in particular water and sanitation, road infrastructure, and electricity access, are crucial for delivering sustainable development and growth. Although these areas are only a selection of SDGs, they exhibit synergies with other goals such as ending poverty and hunger, promoting gender equality, and tackling inequality. These areas are also very important from the point of view of public spending, as they typically represent a large share (about a third) of the government budget.

\section{Pursuing sustainable development in these areas requires additional financing that} could be sizeable for some ASEAN countries. As indicated in the previous section, many ASEAN countries still face challenges in achieving their sustainable development agendas. Ensuring macroeconomic stability, a prerequisite for achieving sustainable economic growth, while expanding spending in critical areas requires a well-defined medium-term financing strategy. The first step in designing such a strategy is costing the needs, and then, identifying the financing-including the decision about the participation of the public versus private sector. While the main elements of the strategy will depend on country circumstances and features, a strong revenue base and increased public spending efficiency should be key pillars for most ASEAN countries.

17. Case studies provide an illustrative analysis of spending needs in education, health, and selected areas of infrastructure. The exercise focuses on two ASEAN countries, Indonesia and Vietnam. The estimates presented in this section cover only a subset of the SDGs, and in that respect, 
should be considered a lower bound of total spending needs in these countries. ${ }^{11}$ Furthermore, spending needs are expected to vary across ASEAN countries, with amounts generally expected to be larger in the lower-middle-income ASEAN economies. ${ }^{12}$

\section{Costs are estimated using as a benchmark the spending levels in countries that exhibit} relatively good performance in these three sectors. The exercise involves several steps (Appendix III). First, using the SDG index for each sector, relatively good performers in the areas of health, education, and infrastructure are identified for each country income group. For example, countries exceeding an SDG education index level of 80 , out of 100 , are considered good performers. Second, the median of the main costing items (for example, for education, this includes teacher salaries, pupils per teacher, and allocation of total expenses between other noncompensation current spending and capital spending) is calculated for these good-performing peers. Third, based on the median values for the good performers, and also taking into account country-specific projections for the country of choice, such as for economic growth and demographics, additional spending needs for 2030 are estimated. The additional spending needs are derived comparing the objective (that is, estimated needs for 2030 consistent with achieving good performance) with the baseline (that is, the current total spending - public and private-in the country under consideration).

\section{A. Indonesia}

\section{The Indonesian government has been strongly committed to achieving the SDGs.}

President Jokowi is the head of the SDG steering committee, and the SDGs have been mainstreamed into national development plans, including the National Visions of Indonesia (Nawacita) and the National Medium-Term Development Plan 2015-2019. Indonesia is also one of the countries that conducts Voluntary National Reviews, with the latest report published in June 2017. Overall, the challenges facing Indonesia in achieving the SDGs are significant and progress has been mixed across areas. A look at SDG indicators shows that Indonesia is much closer in eradicating poverty and taking appropriate climate action, and much further in other areas, including improving health outcomes. A more granular assessment of education, health and infrastructure elsewhere in this section illustrates progress and challenges ahead.

\section{A relatively small increase in government expenditure and enhanced spending} efficiency is needed to close the gap in education outcomes. Currently, government education expenditure stands at 3.6 percent of GDP ( $\$ 516$ per student) and total education expenditure at about 7 percent of GDP. However, Indonesia's performance on education, as measured by the SDG

\footnotetext{
11 The costing exercise-particularly for health and education sectors-is silent about the spending trajectory and variation in composition of spending during the period up to 2030. The structure of spending during the transition period could be different as well—for instance, one can expect more capital and less current expenditures up front.

12 The analysis is part of a broader SDG costing exercise that the IMF has conducted at the request of the United Nations. The findings from this exercise were discussed with the authorities and development partners (World Bank, World Health Organization, Education Commission and United Nations representatives in the field), and at the United Nations on September 24. The five country case studies are Benin, Guatemala, Indonesia, Rwanda, and Vietnam.
} 
index slightly lags the level of countries with good education performance. ${ }^{13}$ The costing exercise suggests that an increase of less than a half percentage point in government education spending would allow Indonesia to close the gap with best performers (Table 1). The analysis also suggests that there is scope to increase the efficiency of spending. For example, teachers' compensation is higher than for peers, partly as a result of the constitutional requirement that at least 20 percent of government expenditure should be spent on education.

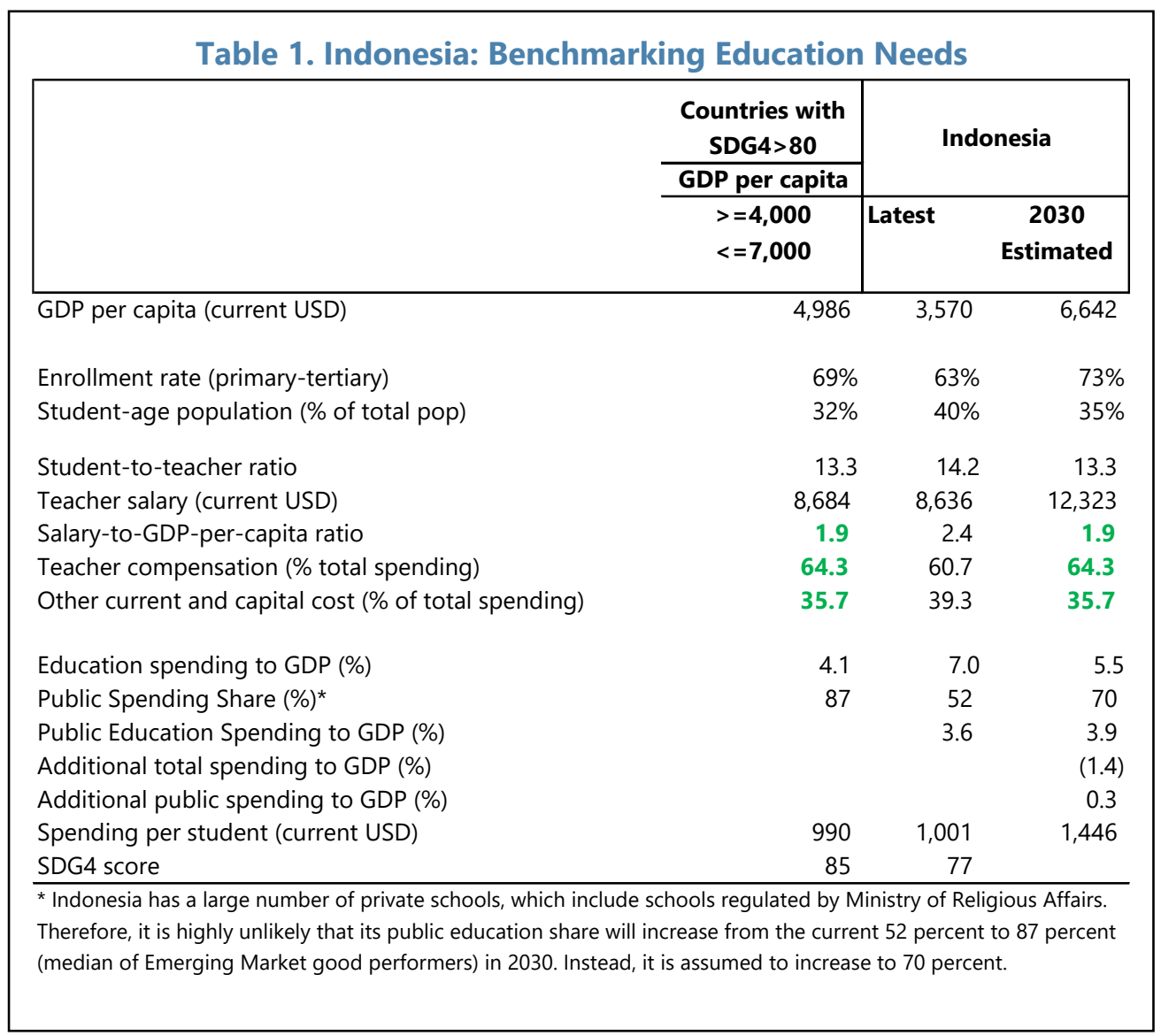

\section{Compared to education, the cost of pursuing better health outcomes could be} significantly higher. There is a considerable gap between Indonesia's health outcomes and that of its peers. Indonesia's health SDG index is 62 as of 2018, compared to the emerging market median of 78. Currently, total health expenditure is about 3.5 percent of GDP per year, of which 1.5 percent of GDP corresponds to public expenditure. Improving health outcomes calls for increasing total health expenditure to close to $61 / 2$ percent of GDP by 2030 . Such an increase would be driven by increases in the number of doctors and other health staff as a share of the population and bringing doctors' average salary in Indonesia to the levels of the best peer performers. Given the authorities' single payer system, a reasonable breakdown in 2030 would be about 60 percent allocated to public expenditure (the average share of the best peer performers), 25-30 percent for out-of-pocket

\footnotetext{
${ }^{13}$ Although the government has committed to a 12-year compulsory education, Indonesia still has enrollment gaps in secondary education, especially in upper secondary education where gross enrollment is 74 percent. Achieving universal enrollment for one year before primary school might be even more challenging. In addition, student performance in Programme for International Student Assessment (PISA) tests is lower than in comparators.
} 
payment, and the rest for private insurance. This results in a government expenditure of almost 4 percent of GDP in 2030 to reach the health objective, an increase of almost $2 \frac{1}{2} 2$ percentage points from the current level.

\section{Additional spending is also needed in the following areas for closing some infrastructure gaps by 2030:}

- Roads. The IMF staff finds that, based on benchmarking and regression analysis, Indonesia would need to build about $173,000 \mathrm{~km}$ of roads during 2018-2030 to raise rural access (the performance indicator for spending needs), from 94 percent to 100 percent. Taking construction and maintenance costs into account, annual road investment would need to reach almost 1 percent of GDP.

- Water. As of 2015, although 86 percent of the urban population had hand-washing access, only two thirds of the rural population had such access. In addition, 5.5 percent of the urban population and more than 20 percent of the rural population still used open defecation. According to two World Bank studies (World Bank 2015, 2016), to achieve the SDG targets of universal safe access by 2030, annual total new investment would need to be $1 / 2$ percent of GDP through 2030, most of which would be covered by the public sector.

- Electricity. Ninety-seven percent of the Indonesian population already has access to electricity, which is close to 100 percent for the median emerging market. However, per capita consumption of electricity is only about 900 kwh per year, well below the emerging market median of 2,679 kwh. If the goals are to achieve universal access and emerging market consumption per capita by 2030, additional investment spending would be almost $1 \frac{1}{2}$ percent of GDP per year.

Figure 8. Indonesia and Vietnam: Total and Public Additional Spending Needs

(In percent of GDP)

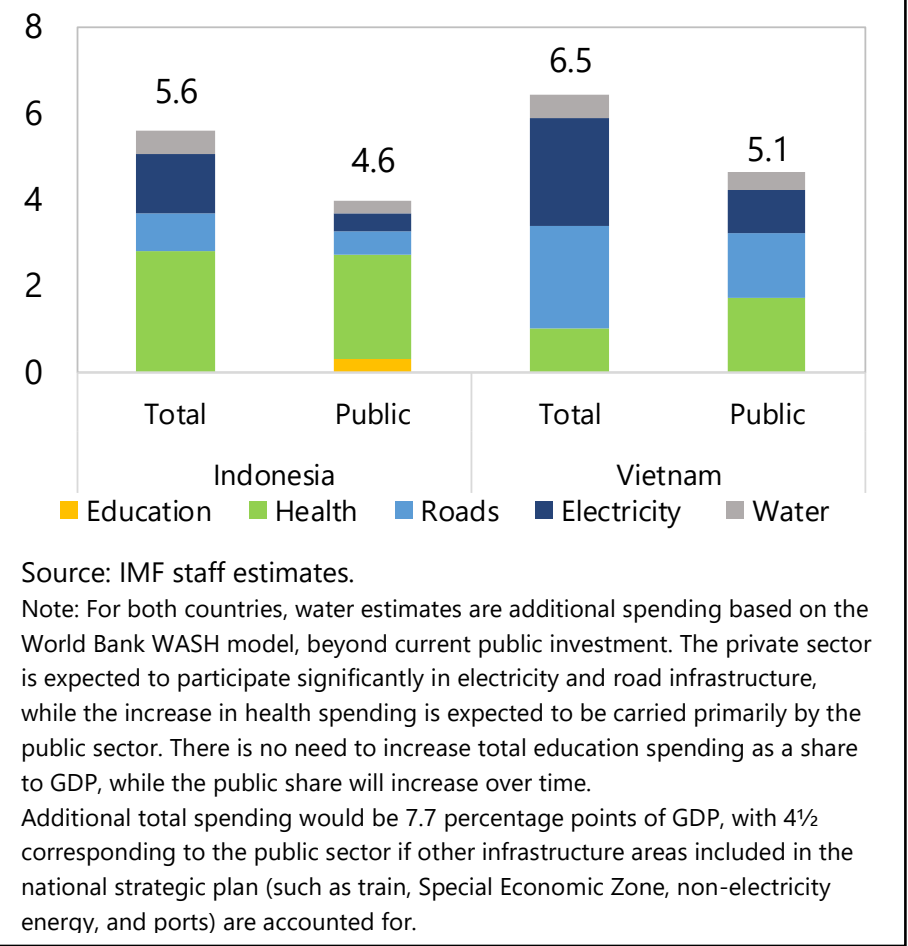

The authorities have launched a medium-term project to increase generation capacity. ${ }^{14}$

\section{Overall additional spending needs to achieve health, education, and infrastructure} goals amount to about 51/2 percent per year. This corresponds to additional public spending in these areas of close to 4 percent of GDP. If the costing includes other infrastructure sectors identified in the national strategic plan, such as train, Special Economic Zone (SEZ), non-electricity energy, and

\footnotetext{
${ }^{14}$ As this increase currently relies mainly on coal, attention should be given to increasing capacity while remaining in line with the Paris commitment.
} 
ports, the total cost increases by 2 percentage points of GDP to nearly 8 percent of GDP (about $41 / 2$ percent of which is expected to be provided by the public sector) (Figure 8). These calculations are broadly in line with estimates from other institutions, including the World Bank, UNESCO, and Schmidt-Traub (2015).

\section{B. Vietnam}

24. The government of Vietnam has shown strong determination in implementing its $\mathbf{2 0 3 0}$ agenda to attain the SDGs. Particular attention is being paid to vulnerable groups such as the poor, people with disabilities, women, children, and ethnic minorities through a number of policies aimed at promoting social equality. After more than 30 years of reforms, Vietnam achieved several of the MDG goals during 2001-2015, such as poverty reduction, universal primary education, and gender equality. Vietnam has now mapped the 17 global SDGs into 115 Vietnam-specific SDG goals in its "National Action Plan for Implementation of the 2030 Agenda for Sustainable Development" to suit the country's context and socioeconomic conditions.

\section{Improving the already good education outcomes in Vietnam hinges on efforts to} address spending inefficiencies. Vietnam has achieved above-average education outcomes in its income group and relatively good education outcomes as reflected in an SDG education index above 80. Vietnam's average enrollment rate (from preprimary to tertiary education) is close to 70 percent, with universal primary education and almost full gender balance. These education results are delivered with a spending of almost 8 percent of GDP ( $\$ 630$ per student). Rather than increasing spending, efforts should be focused on enhancing efficiency of spending. Boosting efficiency, for example by enhancing the allocation of teachers across types of schools (from secondary to preprimary education), would yield the same education outcomes while spending less. Further raising enrollment rates and reducing the already low pupil-to-teacher ratio, currently at 18, to 12 could be achieved with the current spending envelope if efficiency of spending were increased. Education remains a top priority for the government, and the public debate is focused on increasing pre-school access and making lower secondary education universal and tuition free. These further reforms would need additional resources, especially if not accompanied by policy changes that narrow the efficiency gaps.

\section{Vietnam's additional public spending needs for health by $\mathbf{2 0 3 0}$ are estimated at less}

than 2 percent of GDP. Despite good health outcomes in Vietnam, the number of doctors and nurses as a share of the population is still significantly below its best-performing peers, adding to significant overcrowding, particularly at central-level hospitals. At the same time, capital spending is still significant, with a reduction expected over time. On balance, and under these assumptions, achieving even better health outcomes would require additional total health spending estimated at about 1 percent of GDP. Moreover, the share of public spending on health is low at 42 percent and out-of-pocket spending is high. If Vietnam aimed also at a public-sector share in total health spending similar to that of best-performing countries, public health spending would need to increase by more than $1 \frac{1}{2}$ percent of GDP, which implies a proportional decline in out-of-pocket spending. This increase is likely given the current plans to raise health spending more than overall government spending. This reflects both the government's aim to achieve universal health insurance-currently heavily subsidized by government-in the coming years and rising administered health-service fees. 
27. Vietnam's infrastructure needs are large, as growth of water, electricity, and transport infrastructure will need to accommodate rapid economic transformation.

- Roads. Increasing the rural access index by 5 percent, equivalent to an additional 83,000 km of roads, and including maintenance costs of the additional infrastructure, would require an additional 2 percent of GDP per year.

- Water. Based on the World Bank WASH costing model, Vietnam would need to spend an additional $1 / 2$ percent of 2017 GDP per year to provide safe water to all households and end open defecation. This result is mainly driven by the need to expand safely managed water supply.

- Electricity. Full electricity coverage has almost been reached in Vietnam, but the expansion of the current grid and power generation to accommodate the increase in per capita electricity consumption (estimated at an average 8 percent annual growth) will require significant resources, up to 3 percent of GDP per year.

28. Overall additional spending needs to achieve health, education, and infrastructure goals amount to almost $61 / 2$ percent per year (Figure 8). In the absence of public spending plans, uncertainties about targets in some sectors, data gaps, and uncertainties surrounding private sector participation, these estimates should be understood as a general approximation rather than precise forecasts. The total share of additional government spending that is needed is estimated at around 5 percentage points of GDP. ${ }^{15}$

\section{Approaches for Financing}

\section{Achieving the SDGs will require an increase in total and public spending in ASEAN} countries, which could be sizeable in some countries. Countries can only realistically achieve relevant development goals when they are able to identify and mobilize the required financing. The financing strategies will vary across countries and depend on, among other factors, the size of the spending needs. Also, needs in each sector may lend themselves to a different financing approach, in particular depending on the availability of private sector financing. Moreover, there may be a limited substitutability between public and private financing for development in some areas such as education.

30. When the additional spending is undertaken by the public sector, the identification of public resources should be anchored in a medium-term revenue strategy (MTRS). Such a strategy should reflect, among other things, tax capacity and room that are available to enhance spending efficiency.

\footnotetext{
${ }^{15}$ As noted earlier, spending needs are likely to vary and may be larger for lower-middle-income ASEAN countries. For example, a separate costing exercise conducted in the context of the 2018 Article IV consultation for Myanmar suggests that Myanmar would require an additional 21/2 percent of GDP a year in both education and public health spending to achieve its SDGs in these two areas (IMF 2018a). The estimated total additional spending at 5 percent of GDP a year is therefore significantly higher than the comparable estimate for Vietnam and Indonesia (about 2 and 3 percent of GDP, respectively).
} 
- Tax capacity. When government tax revenues fall short of the revenue-mobilizing potential compared to countries in the same income group, mobilizing domestic revenues should be the main source of financing for the SDGs. As in most ASEAN countries, Indonesia's general government revenue is less than 15 percent and tax revenue around 11 percent of GDP, well below emerging market peers, suggesting ample room to increase domestic revenue. Indeed, an MTRS for Indonesia identified additional potential revenue of about 5 percent of GDP (3.5 percent from tax policy reform and 1.5 percent from revenue administration reform) (De Mooij, Nazara, and Toro 2018). The yields from this additional revenue could be used to cover financing needs for health, education, and infrastructure in Indonesia.

- Enhancing spending efficiency and rationalizing other spending. Increasing spending efficiency or rationalizing nonpriority spending — such as eliminating energy subsidies, which are inefficient and inequitable-and implementing carbon pricing should also contribute to generating a part of the needed fiscal room and complement revenue raising efforts. Therefore, an assessment of expenditures is warranted and needs to be taken within the context of competing demands for spending and prioritizing development needs. For Vietnam, for instance, there is limited room to further increase the revenue-to-GDP ratio as reflected in a revenue ratio at $231 \frac{1}{2}$ percent of GDP (19 percent for tax revenue) that compares favorably with peers. Thus, efforts should instead be focused on pursuing spending efficiency gains.

- Assessing fiscal sustainability and space under fiscal rules. Additional government borrowing, if it does not endanger market access and debt sustainability, could finance a part of the needed increase in spending on health, education, and public infrastructure. Spending in crucial areas for growth and development should in turn improve debt sustainability. Still, this may not always be an option. For instance, both Indonesia and Vietnam have prudent debt or deficit ceilings, which limit the role of debt financing in achieving the SDGs. Given Indonesia's mandatory 3 percent government deficit ceiling, there is little fiscal space within the fiscal rule. In the case of Vietnam, public debt-at 58 percent of GDP in 2017-is relatively close to the statutory debt limit of 65 percent.

31. Institutional and delivery capacity aspects are also crucial for ensuring that the additional government spending leads to the desired SDG outcomes. These include mediumterm budget planning, capacity development, and adequate governance. Digitalization, relatively widespread in ASEAN countries, can provide further opportunities for improving the design and implementation of fiscal policy (Box 3).

32. Private sector participation-including through public-private partnerships (PPPs)— could also help fill the financing gap. Vietnam is developing a new PPP law as it is aiming to increase private sector participation to mobilize additional financing for investment and some areas of development (particularly for infrastructure). Much of the preprimary education is likely to remain privately funded. Hospitals are increasingly reliant on fees and charges, and out-of-pocket spending on health is projected to remain high. In the case of PPPs, countries need to ensure these financing schemes deliver value for money vis-a-vis traditional procurement in order to minimize the potential fiscal costs and risks arising from these projects. 


\section{There may be a role for the international community to step in to help fill in the} financing gap. Significant increases in public spending supported by resource mobilization and spending efficiency efforts, as well as in private sector provision, may not be enough to close the financing gap. This could be the case in some lower-middle-income ASEAN countries with large sustainable development needs and with low levels of revenue-generating capacity. In those cases, additional external concessional financing from development partners would likely be required.

\section{Box 3. Fiscal Policy Goes Digital in ASEAN Countries}

Digitalization offers the opportunity to improve the design and implementation of fiscal policy. Governments are using digital tools for tax and expenditure policy, public financial management, and public service delivery. Electronic tax filing, digital payments, and verification of customs and business activity can increase revenues by strengthening tax compliance, thereby creating fiscal space for scaling up development spending. Better identification and authentication through biometric technology can reduce leakages in social spending and improve the coverage of targeted populations. Digital tools can also improve the delivery of public services through online applications that facilitate communication with citizens. Finally, the use of digital tools can increase operational efficiency by enhancing, for instance, public procurement.

\section{Applications of digitalization in the region are diverse, and many can assist sustainable} development. Many Association of Southeast Asian Nations (ASEAN) member countries (Singapore, Thailand, Malaysia, and Indonesia) are moving towards a form of digital ID to underpin their digitalization efforts. The Philippines' digital registry covers 75 percent of the population and is used to determine eligibility for 52 social programs. Other examples include electronic benefit transfer cards used in Thailand and Indonesia and online digital services, which are growing in countries like Singapore. In addition, in Singapore, the Elderly Monitoring System monitors older citizens' daily activities at home with the use of a network of wireless sensors and text-to-speech apps, empowering the elderly to live longer independently. This Figure 3.1. Government Digitalization (Digital Adoption Index for Governments, latest year available)

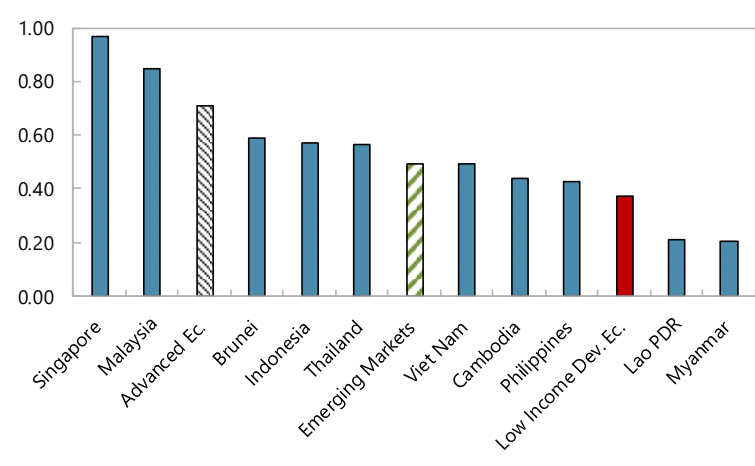

Source: World Bank and UN could reduce the cost of nursing homes and the public spending pressures from an aging population. Another common development is the digitalization of the revenue administration which allows for e-filing, e-payments (Singapore, Malaysia, Vietnam, Indonesia, Thailand) or the adoption of e-customs (Singapore, Vietnam).

Digital technologies are rapidly growing in ASEAN countries, with some countries operating at the frontier. For example, Singapore and Malaysia are among the top 10 performers according to the World Bank's Digital Adoption Index (Government) (Figure 3.1). Countries such as Brunei, Indonesia, and Thailand score higher on government digitalization than the average of emerging markets. The adoption of government digitalization in Vietnam and Cambodia is higher than the average of developing countries. 
Digitalization also brings many challenges. Digitalization requires that citizens and businesses have access to digital tools and are able to use these tools effectively. But access to technology remains elusive in many countries-for example in Lao P.D.R., Myanmar, Indonesia, and Cambodia less than one-

\section{Box 3. Fiscal Policy Goes Digital in ASEAN Countries (concluded)}

third of the population has access to the internet. Digital databases have also created new challenges for privacy, fraud prevention, and cybersecurity. While ASEAN countries have taken steps to mitigate these threats, in April 2018, ASEAN countries reaffirmed the need to build close cooperation and coordination among member states on cybersecurity policy development and capacity building initiatives.

\section{THE IMF'S SUPPORT FOR ASEAN}

34. The IMF continues to engage ASEAN countries in key areas linked to the achievement of the SDGs through policy advice and support for national capacity-building efforts (Figure 9). In line with their mandates, ASEAN and the IMF both strive for economic growth and sustainable development through economic integration and policy collaboration among the member countries. The IMF has strengthened its engagement with ASEAN countries through its policy diagnostics, advice, and capacity-building efforts to support their policy efforts for pursuing the SDGs. This also includes close engagement with ASEAN on the ground through the IMF Regional Office for Asia and the Pacific, two regional centers for capacity development in ASEAN, the Singapore Regional Training Institute, and the Capacity Development Office in Thailand, as well as resident representative offices in the majority of the ASEAN countries. The IMF has also stepped up its engagement with the ASEAN +3 Macroeconomic Research Office (AMRO), with a Memorandum of Understanding on AMRO-IMF collaboration signed by the IMF Managing Director and the AMRO Director in October 2017. In the context of the 2030 Development Agenda, the IMF has provided support to ASEAN countries under new initiatives that it has committed to in the areas of strengthening resource mobilization, building state capacity for infrastructure provision, pursuing economic and financial inclusion, and addressing the challenges of climate change, it is also expanding its support for countries in building strong economic institutions and limiting vulnerabilities to corruption. In addition, the IMF has worked with ASEAN countries to improve statistical capacity, including support to national statistical agencies in establishing their own SDG indicators framework and intensified its efforts to implement the enhanced General Data Dissemination System (e-GDDS) (Appendix IV). 
Figure 9. The IMF's Capacity Development Priorities and the SDGs

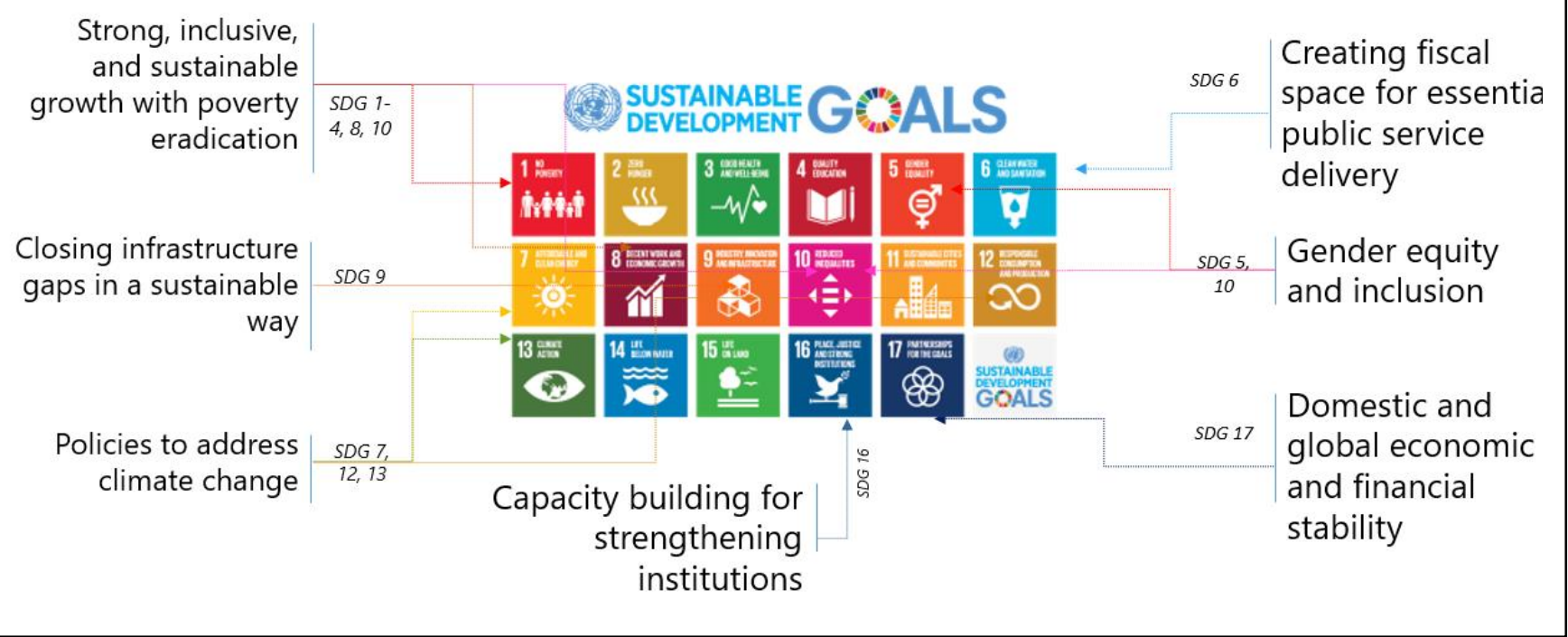

\section{A. Strengthening Resource Potential}

\section{The IMF has committed to enhance its support for developing countries to strengthen} their tax capacity. Over the past two decades, most developing ASEAN countries have strengthened their revenue collection, reaching or going beyond the level of developing countries in the region (Figure 10). Cambodia and Myanmar, two of the main ASEAN recipients of IMF technical assistance (TA), stand out for their effort, in particular since 2015. However, in most countries tax revenue-to-GDP ratios are still below 15 percent, highlighting the great challenge ahead. Since 2015, the IMF has heightened its

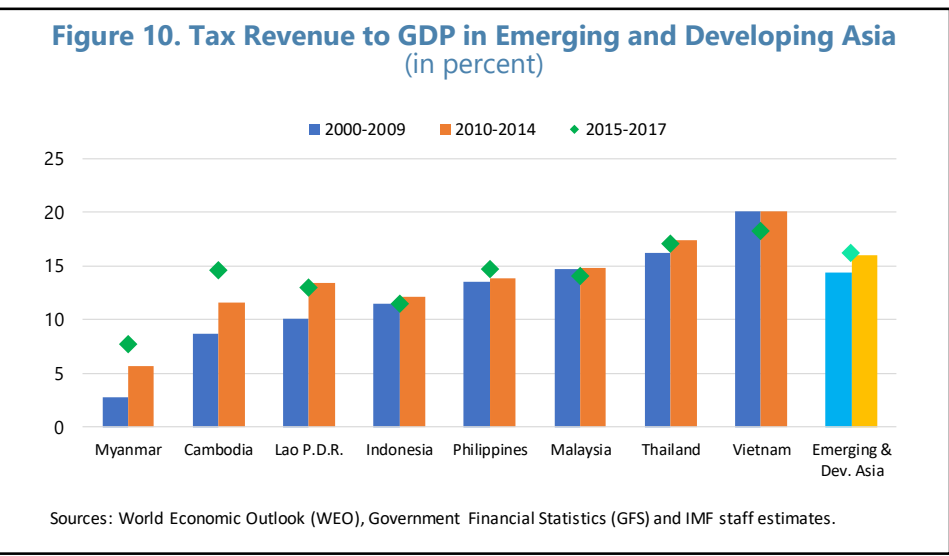
engagement in developing countries through various initiatives-including Medium-term Revenue Strategies (MTRS) and the Platform for Collaboration on Tax (PCT) - to support them to boost their revenue potential and strengthen their voice in the dialogue on international tax issues (Appendix IV).

\section{Since 2015, the IMF has significantly scaled up its engagement in ASEAN countries,} providing support to their reform process. Assistance, mostly to developing ASEAN countries through TA missions, and applications of toolkits for assessing tax administrations and revenue gaps (Tax Administration Diagnostic Assessment Tool (TADAT), Revenue Administration Gap Analysis Program (RA-GAP), and Revenue Administration Fiscal Information Tool (RA-FIT/ISORA) and tax policy (Tax Policy Assessment Framework (TPAF)), increased by about 30 percent since 2014. ASEAN countries have taken several steps in these areas. For example, the Philippines authorities recently introduced a new law aimed at mobilizing revenue for an infrastructure investment program. In 
Vietnam, the authorities have introduced a new tax management information system, a risk management board, and a centralized call center. Other on-going reforms aim at improving audits, anti-smuggling and anti-tax evasion. Moreover, significant progress has been made on advancing IT infrastructure. In Myanmar, institutional strengthening has led to a range of new taxpayer services and reinforced the tax filing processes and procedures. The authorities are working on the implementation of the new information technology system and tax administration law. Moreover, the promulgation of new income tax legislation is under consideration. In Lao PDR, a revised valueadded-tax (VAT) law was recently approved and plans are underway to replace the General Tax Law. Also, the authorities have established a Planning and International Cooperation committee, whose responsibility is to implement the tax administration plan, as well as to coordinate with donors and international organizations. A MTRS has been developed in Indonesia and Thailand, and is underway in Lao PDR.

\section{Although the fruits of tax reforms take time to materialize, efforts have started to pay} off in some countries (Figure 11). For example, in the Philippines, the VAT revenue-to-GDP ratio has increased thanks to a substantial reduction of VAT exemptions. Cambodia and Myanmar are other countries where the authorities have taken steps to strengthen tax and customs administration, which have led to a significant increase in tax collection.

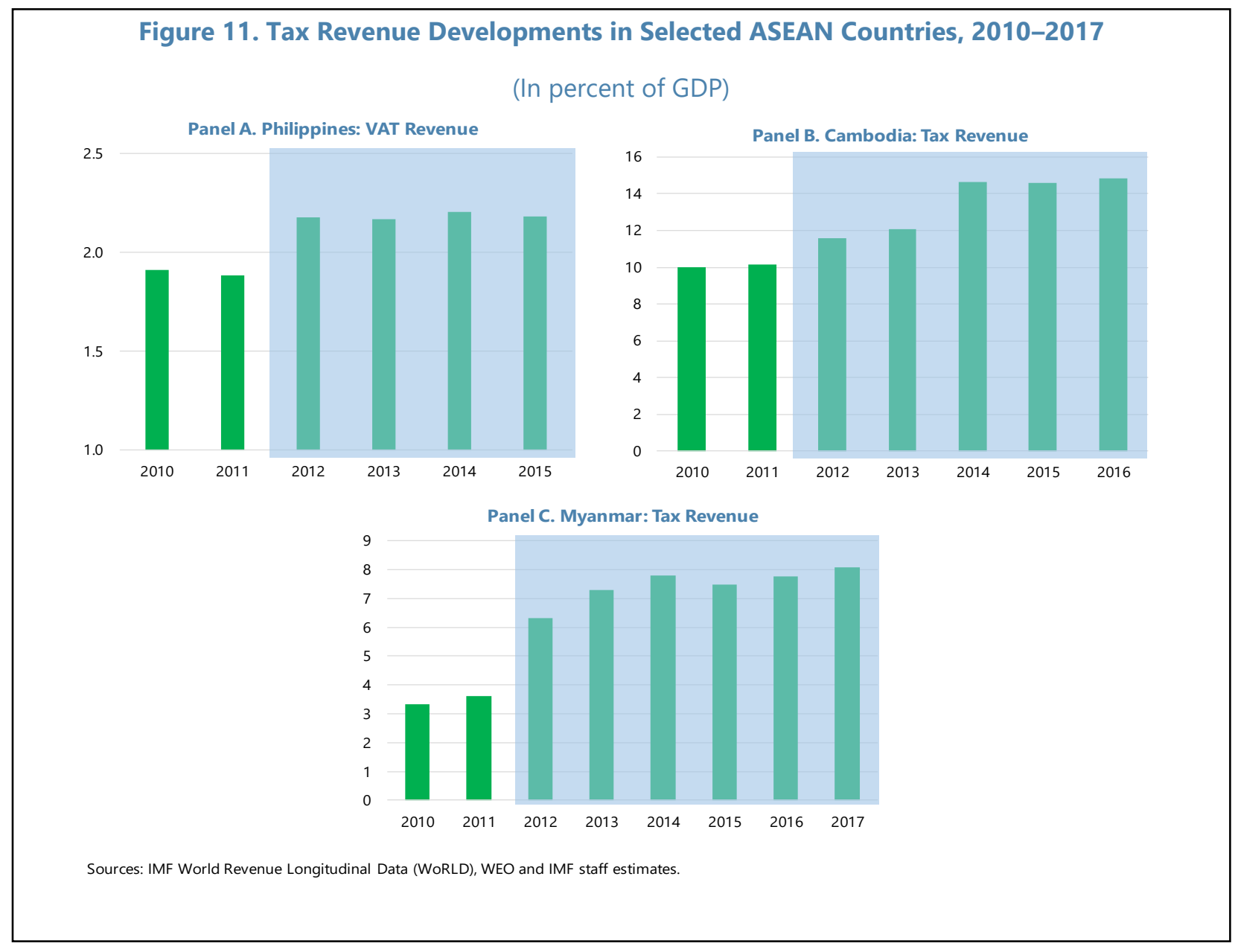




\section{B. Building State Capacity for Infrastructure Provision}

38. Expanding infrastructure in ASEAN countries in a fiscally responsible manner can help enhance productive capacity, promote inclusion, and thereby support their development agenda in a sustainable manner. Most ASEAN countries face large infrastructure gaps. According

to the Global Infrastructure Hub estimates, ASEAN countries need to invest an additional US\$35 billion per year through 2030 in infrastructure to attain the SDGs (Figure 12). ${ }^{16}$ The infrastructure investment gap is particularly large for Cambodia and Myanmar at 78 and 186 percent of the current investment level, respectively, while it is only 0.3 percent for Singapore. Scaling up infrastructure investment is a key component of

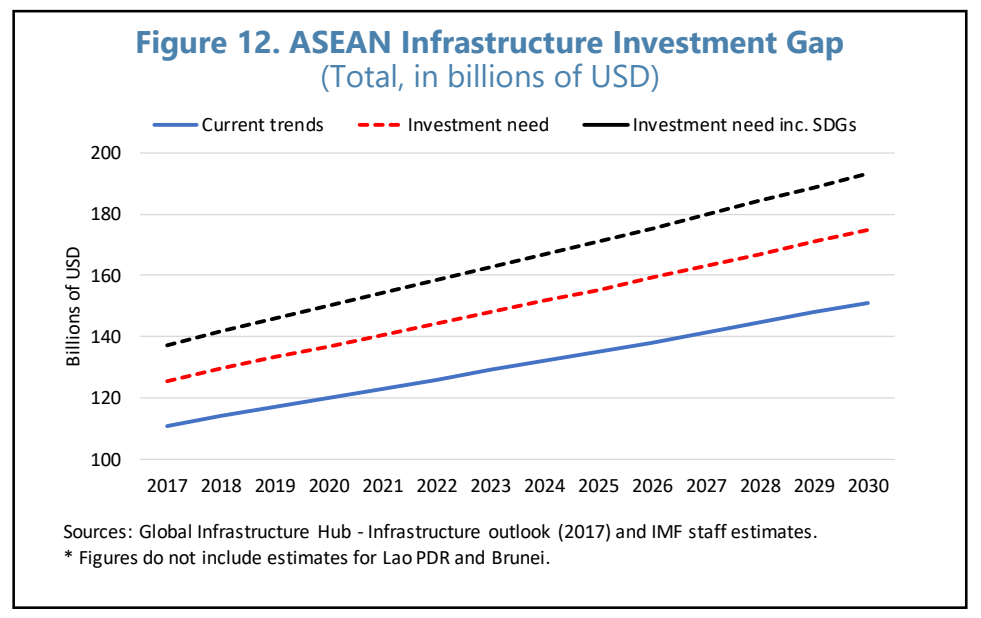
many ASEAN countries' national development plans.

39. The IMF launched an Infrastructure Policy Support Initiative (IPSI) in $\mathbf{2 0 1 5}$ to support countries seeking to improve their infrastructure in a sustainable and efficient manner. The IPSI consists of a collection of tools that allow to (i) assess of public investment management (Public Investment Management Assessment, PIMA); (ii) assess of fiscal risks associated with PPPs (PublicPrivate Partnerships Fiscal Risk Assessment Model, P-FRAM); (iii) analyze macroeconomic and fiscal implications of public investment scaling-up; (iv) assess the sustainability of fiscal policy (Debt Sustainability Analysis, DSA); and (v) optimize the government's debt portfolio (Medium-Term Debt Management Strategy, MTDS) (Appendix IV).

40. IMF recommendations based on PIMA have provided inputs to policy dialogue. For example, in Thailand, although public investment efficiency and public investment institutions are better than in other developing economies, the PIMA analysis shows important institutional weaknesses in planning and budgeting processes, and in transparency of budget execution. In this context, the authorities have taken measures that have helped reduce the delays in procurement. Similarly, in Malaysia, notwithstanding the strong public investment institutions, PIMA identified weaknesses in project programing, appraisal, and selection, leading to delays in project implementation. In recognition of these shortcomings, the authorities requested further technical assistance on strengthening investment processes.

41. TA findings on fiscal risks associated with PPP projects have guided the design of PPP frameworks. For instance, in Cambodia, investment financed by PPPs has grown considerably, thus elevating fiscal risks. The P-FRAM analysis shows that the institutional framework is not sufficient to control the fiscal costs and risks created by PPPs. The authorities have recognized the need for

16 The Global Infrastructure Hub Outlook (2017). The estimate does not include Lao PDR and Brunei. 
strengthening their framework and subsequently created the Central PPP Unit to oversee projects. They have also planned to include risks of contingent liabilities from PPPs into the next Public Debt Management Strategy.

\section{Analysis based on the Debt-Investment-Growth (DIG) model has facilitated the} comparison of alternative investment trajectories and financing modes in a number of ASEAN countries. The DIG and Debt, Investment, Growth, and Natural Resources (DIGNAR) models have been applied to Cambodia, Myanmar, Thailand, and Vietnam. The main finding of all the applications is that public investment helps boost growth, but overly ambitious scaling-up plans may pose serious threats to public finances. For instance, the DIG model applied to Cambodia and Vietnam shows that a gradual public investment scaling-up financed by borrowing and fiscal adjustment along with higher revenue collection efficiency would lead to the best macroeconomic outcomes. In addition, enhancing the efficiency of public investment uniformly magnifies the positive effect on growth and improves debt dynamics. The DIGNAR applications emphasize the necessity of delinking government expenditures from the booms and busts of commodity prices and building fiscal buffers. For instance, the application of DIGNAR to Myanmar suggests that future gas revenue streams in Myanmar should be used to finance a gradual scaling up in public investment while building fiscal space and maintaining a stable macroeconomic environment.

43. DSA and MTDS are widely used in capacity development. DSA and MTDS are important components of several courses offered by the Fund's Institute for Capacity Development (ICD) and regional training institutes. About 270 government officials from the ASEAN countries have been trained in DSA during 2014-17. Moreover, DSA is the subject of ICD's two online courses that have been introduced in recent years. Beyond classroom and online training, the Fund provides considerable hands-on technical assistance. For example, since 2014 the Fund has provided a fiveday technical workshop on DSA to Cambodia, Lao PDR, and Myanmar, as part of the Fund's annual regional training program.

\section{Pursuing Economic and Financial Inclusion}

44. While the IMF has long recognized the importance of inclusion, since 2015 it has adopted a more systematic and structured approach (Appendix IV). Recent empirical work by the IMF finds that lower inequality is correlated with faster and more robust growth (Ostry, Berg, and Tsangarides, 2014; Dabla-Norris and others, 2015). Also, macroeconomic policies and reforms key for growth may have adverse distributional implications, which in turn can undermine public support for reforms (Fabrizio and others, 2017). Furthermore, recent IMF work has discussed how fiscal policy, the main policy tool for redistribution, can help address inequality (IMF, 2017a). Promoting economic and financial inclusion involves addressing income inequality, women's economic empowerment, and inequality in access to, and use of, financial services.

\section{Addressing Income Inequality and Gender Gaps}

45. The IMF has intensified its engagement with ASEAN countries on issues of gender and inequality through policy advice, technical assistance and capacity building. 
- Inequality. Under the inequality pilot initiative (Appendix IV), an analysis of intergenerational issues was conducted for Singapore, a country that is aging at a much faster rate than other advanced economies. Making use of a recently developed model-based framework, staff has analyzed the macroeconomic and distributional impact of financial reforms in Myanmar, showing that gradual financial liberalization would boost growth while reducing inequality and poverty. Inequality-related issues will be also analyzed in Cambodia and Lao PDR in the next Article IV cycle as part of the pilot initiative on inequality.

- Gender. Work on gender-related issues is ongoing in Lao PDR and Vietnam. The IMF has provided technical assistance to Cambodia on implementing gender budgeting in the context of public financial management reforms, and recently offered a regional seminar that was attended by representatives from Indonesia, Thailand and Philippines.

46. In general, ASEAN countries have welcomed IMF advice and engagement in support of their strategies for making growth more inclusive. They have been taking actions to address both economic and gender inclusion. Some examples include:

- Inequality. Myanmar has developed the Myanmar's Sustainable Development Plan for achieving the SDGs, including inclusive growth, that identifies its development priorities. Singapore introduced a "Smart Nation Initiative" to support better living using technology that involves public administration reform such as cross-government digitalization efforts. It provides targeted transfers to promote inclusion, worker retooling and lifelong learning as they undergo structural transformation to the knowledge-based economy. Thailand is currently implementing a new social transfer scheme.

- Gender. Malaysia is aiming to raise female labor force participation to 59 percent by 2020 and has put in place measures to incentivize women to stay at work such as tax incentives to companies for setting childcare facilities and encouraging them to allow flexible work arrangements. In the Philippines, various legislative measures that seek to amend discriminatory provisions of existing laws are currently under consideration by Congress. Also, the authorities are aiming at raising female labor force participation by 2 percent by 2022 including by improving access to affordable childcare. 


\section{Promoting Deeper, More Inclusive and Stable Financial Systems}

\section{The IMF has heightened its engagement with ASEAN countries in key aspects of} financial stability. Since 2015, the IMF has provided 37 TA missions in ASEAN countries covering various aspects ranging from crisis management and deposit insurance, supervision and regulation, macroprudential policy, financial soundness indicators (FSIs), to balance sheet analysis (Figure 13). Beneficiary countries include Brunei, Cambodia, Indonesia, Lao PDR, Myanmar, Philippines, Thailand, and Vietnam. In addition, two workshops on FSIs were conducted in Thailand in 2016 and 2017. In

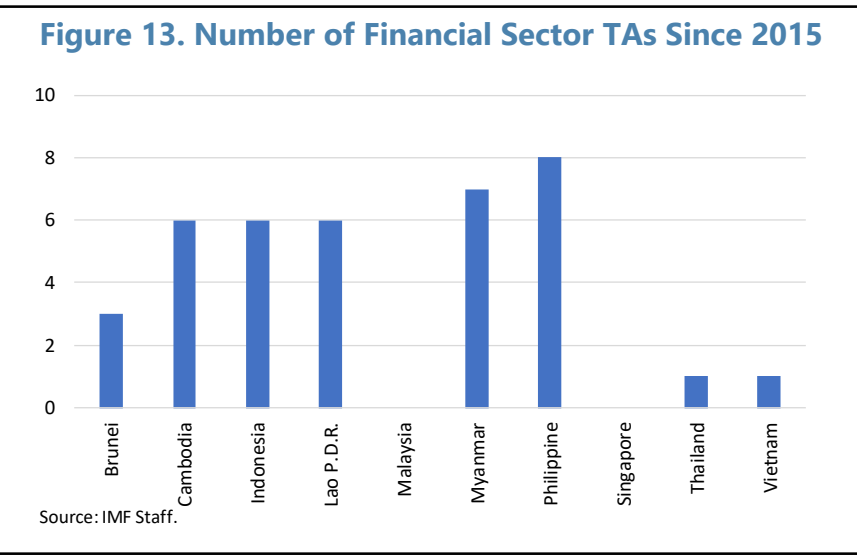

2017, the IMF developed the Financial Sector Stability Review (FSSR) targeted to low- and middleincome countries, which explores, among other things, the nexus between financial inclusions and financial stability. An FSSR is scheduled for Cambodia in the 2018-19 fiscal year. The IMF has also developed the Financial Access Survey dataset and is the official custodian of the SDG financial inclusion indicators.

48. ASEAN countries are striving to develop their financial systems and making them more inclusive. For instance, the Indonesian authorities created a high-level joint forum for financial deepening and the National Council for financial inclusion to promote interagency coordination. The increasing use of digital financial services is helping the country to overcome geographical barriers to financial inclusion. In Myanmar, the central bank has established the regulatory framework for mobile financial services to enable mobile network operators to offer mobile financial services. Also, the authorities passed regulations to facilitate the development of the microfinance sector. In Cambodia, the authorities have formulated a financial inclusion strategy and are further developing financial infrastructure, including a new electronic payment system to facilitate riel transactions. The central bank together with the Ministry of Education are taking steps to improve financial literacy.

\section{Addressing the Challenges of Climate Change}

49. The IMF's energy/climate initiative supports countries in adopting policies to reduce the macroeconomic risks posed by climate change and help build resilience and adaptation. The IMF has been helping member countries implement their mitigation pledges for the Paris Agreement, and has strengthened dialogue on climate resilience and energy price reform in surveillance (Appendix IV). Under the initiative, studies for Myanmar, Thailand, and Vietnam have been completed. The centerpiece of the climate/energy initiative is the development of spreadsheet tools for estimating carbon prices needed to meet mitigation commitments, their broader environmental, fiscal, and economic impacts, and tradeoffs with other (fiscal and regulatory) instruments. The carbon pricing tools have been completed for G20 countries (including Indonesia) and will be finalized for all ASEAN countries by Fall 2018. 
50. The IMF has been supporting ASEAN countries as they develop their strategies to address climate change challenges. For instance, in Vietnam, the authorities developed a national strategy to improve resilience to climate change, strengthen the country's adaptability, and adopt a more sustainable growth model. They have levied higher taxes on natural resource use to reduce their exploitation. Energy subsidy reforms were undertaken in Thailand and Indonesia. Carbon tax and emission trading systems are currently under consideration in Singapore, Thailand and Vietnam.

\section{E. Strengthening Institutions for Good Governance}

51. The IMF is stepping up its engagement with member countries on strengthening economic institutions and containing vulnerabilities to corruption-a critical pillar for achieving the SDGs. Recent work by the IMF finds that corruption and weak governance are associated with lower growth, investment, and tax revenue collection and with higher inequality and social exclusion (IMF, 2016, 2017d, 2017e, 2018b). Evidence shows that successful anti-corruption initiatives are built on institutional reforms that emphasize transparency and accountability. For this reason, the IMF is stepping up its engagement on governance and corruption, focusing on building strong economic institutions. In April 2018, the IMF adopted an enhanced framework to assess corruption vulnerabilities across its membership (see Appendix III). The new framework covers: (i) fiscal governance; (ii) financial sector oversight; (iii) central bank governance; (iv) market regulation; (v) rule of law; (vi) anti-money laundering and combating the financial terrorism; and (vii) corruption. It calls for the IMF to enhance its engagement on governance and strengthen its coverage of corruption issues across its membership, in a systematic manner that ensures evenhanded treatment of countries.

52. The IMF is committed to enhance its support to ASEAN countries as they work to strengthen institutions and ensure good governance. Since the adoption of the new framework, the IMF has prepared governance assessments for a few countries, which will be discussed with country authorities as part of the regular Article IV consultation process. The framework is expected to be rolled out to cover all IMF member countries, including ASEAN countries.

\section{CONCLUSIONS}

53. ASEAN countries are well on their way toward better sustainable development outcomes. Strong income and consumption growth in recent years has paved the way towards reduced poverty, improved health and education outcomes, and greater inclusion, to varying degrees across the ASEAN countries. As a result, as suggested by the summary indicator, economic welfare has improved. Supported by continued income gains and assuming that past trends for sustainable development indicators continue, economic welfare in ASEAN countries is expected to continue converging towards advanced Asia levels. Most ASEAN countries are on track to eradicate absolute poverty by 2030, a major milestone for the region.

54. Strong policy efforts are needed to support further gains in sustainable development. Analysis shows common challenges across the ASEAN countries. In particular, despite some progress, inequalities remain in several ASEAN countries and the shift towards manufacturing strains 
environmental sustainability, Also, more determined efforts and additional fiscal spending are needed to improve education, health, and infrastructure outcomes. Progress towards SDGs could be accelerated by country-specific policy efforts, including additional fiscal spending on priority areas within a well-defined financing strategy, supported by cooperation among ASEAN countries in policy implementation.

- Policies. Achieving more balanced, inclusive, and environmentally sustainable development outcomes calls for comprehensive, country-specific policy strategies. Policies to improve environmental sustainability could include, for example, reducing distortions in fuel pricing and reducing energy subsidies as well as potential tax policy measures such as introducing carbon taxation. Examples of policies that can help reduce income inequality include increasing reliance on progressive direct taxes and strengthening targeted social spending to improve safety nets.

- Spending needs. While development needs will vary across countries, cost estimates suggest large spending needs for most ASEAN countries. For the lower-middle-income ASEAN countries in particular, more determined policy efforts are needed to further improve health and education outcomes and infrastructure. This will require higher spending in these priority areas, continued improvements in revenue mobilization, and spending efficiency.

- Financing. Meeting these spending needs will require improvements on multiple fronts. Additional public spending should be anchored in a medium-term revenue strategy that reflects improving tax capacity and spending efficiency as well as ensuring supportive institutional environment. The remaining financing gap could be filled through private sector participation, and for developing ASEAN countries, concessional financing from development partners.

- ASEAN cooperation. Finally, the further strengthening of collaboration and economic integration among ASEAN countries envisaged in the ASEAN Economic Community Blueprint 2025 holds great promise. Given the challenges many countries face in implementing the SDGs, further cooperation in using data to monitor and evaluate progress, as well as sharing experiences in developing national action plans, may be helpful.

\section{In line with its mandate, the IMF stands ready to continue its engagement with ASEAN} and its member countries in their effort to pursue the SDGs. Both the ASEAN community and the IMF strive for economic growth and sustainable development through economic integration and international policy collaboration. The IMF, in accordance with its role and mandate and drawing on a range of tools and expertise, is prepared to support its members in these important efforts. 


\section{References}

Annett, T., and Lane, C. (2018): "5 Things You Need to Know about the IMF and Sustainable Development Goals", IMF Blog, available at [...]

ASEAN (2017): "Fifth ASEAN State of the Environment Report", Jakarta.

Asian Development Bank (2017): "Meeting Asia's Infrastructure Needs", Manila.

Bannister, Geoffrey and Alexandros Mourmouras (2017): "Welfare vs. Income Convergence and Environmental Externalities", IMF working paper.

Baum, Anja (2018): "Vietnam-Spending Needs for Reaching the SDG Goals".

Dabla-Norris, Era, Kalpana Kochhar, Nujin Suphaphiphat, Frantisek Ricka, Evridiki Tsounta. 2015. "Redistribution, Inequality, and Growth," IMF Staff Discussion Note, SDN/15/13

De Mooij, R., Nazara, S., and Toro, J. (2018): "A Medium-Term Revenue Strategy for Indonesia, Realizing Indonesia's Economic Potential", IMF, Washington D.C.

ESCAP (2018): "Asia and the Pacific SDG Progress Report 2017".

Fabrizio, Stefania, Davide Furceri, Rodrigo Garcia-Verdu, Bin Grace Li, Sandra V. Lizarazo, Marina Mendes Tavares, Futoshi Narita, and Adrian Peralta-Alva. 2017. "Macro-Structural Policies and Income Inequality in Low-Income Developing Countries," SDN/17/01

Fay, Marianne, and Tito Yepes, 2003, "Investing in infrastructure: what is needed from 2000 to 2010?" World Bank Policy Research Working Paper 3102.

http://documents.worldbank.org/curated/en/502041468739488372/pdf/multiOpage.pdf

Global Infrastructure Hub. 2018. "Global Infrastructure Outlook: Infrastructure investment needs 50 countries, 7 sectors to 2040." Global Infrastructure Hub.

Gupta et al. 2017. Digital Revolutions in Public Finance. IMF. https://www.elibrary.imf.org/view/IMF071/24304-9781484315224/24304-

9781484315224/24304-9781484315224.xml

Hutton, Guy and Mili Varughese, 2016, "The Costs of Meeting the 2030 Sustainable Development Goal Targets on Drinking Water, Sanitation, and Hygiene," Water and Sanitation Program: Technical Paper. http://wwwwds.worldbank.org/external/default/WDSContentServer/WDSP/IB/2016/02/08/090224b08415bd $\mathrm{ca} / 1$ 0/Rendered/PDF/The0costs0of0m0itation00and0hygiene.pdf

IMF. 2015a. "Financing for Development-Revisiting the Monterrey Consensus." Policy Paper, Washington.

- 2015b. "The Role of the IMF in Supporting the Implementation of the Post-2015 Development Agenda," Policy Paper, Washington.

- 2015c. "The Managing Director's Statement on the Role of the Fund in Addressing Climate Change," Washington. https://www.imf.org/external/np/pp/eng/2015/112515.pdf

- 2015d. Thailand Article IV Consultation Report, Appendix III

_ 2015b. "Financing for Development: Enhancing the Financial Safety Net for Developing Countries." Policy Paper, IMF, Washington.

_ 2016, "Corruption: Costs and Mitigating Strategies," Staff Discussion Note 16/05, May, available at: http://www.imf.org/external/pubs/ft/sdn/2016/sdn1605.pdf [last visited March 8, 2018]

2017a. Fiscal Monitor: Tackling Inequality, October (Washington). 
2017b. Myanmar Article IV Consultation, Appendix IV

-2017c. "Gender Budgeting in G7 Countries." Washington, DC.

- 2017d, "The Role of the Fund in Governance Issues - Review of the Guidance Note Preliminary Considerations" August, available at: http://www.imf.org/en/publications/policypapers/issues/2017/08/01/pp080217-the-role-of-the-fund-in-governance-issues-review-of- theguidance-note [last visited March 8, 2018]

- 2017e, "The Role of the Fund in Governance Issues - Review of the Guidance Note Preliminary Considerations - Background Notes", Staff Supplement, August https://www.imf.org/ /media/Files/Publications/PP/2017/pp080217-the-role-of-the-fund- ingovernance-issues-review-of-the-guidance-note.ashx.

2018a, "'Poverty Dynamics and Sustainable Development Goals (SDGs)", Selected Issues Paper, IMF Country Report No. 18/91 (Washington).

-2018b, "Review of 1997 Guidance Note on Governance-A Proposed Framework for Enhanced Fund Engagement, SM/18/55, April (Washington DC)

Jin, Hui (2018): "Indonesia-Spending Needs for Reaching the SDG Goals".

Jones, Charles and Peter Klenow (2016): "Beyond GDP? Welfare Across Countries and Time", American Economic Review 106(9).

Kolovich, L., ed. 2018. Fiscal Policies and Gender Equality, Washington DC: International Monetary Fund.

Lagarde, C. and V. Gaspar (2018). [SDG costing work], IMF Blog forthcoming.

Ostry, J., Berg, A. and Tsangarides, C. (2014): "Redistribution, Inequality and Growth", IMF Staff Discussion Note.

Overseas Development Institute (2016): "Projecting Progress: The SDGs in Asia and the Pacific" Prady, D., M. Soto, and D'Angelo's (2018). "Cost of Reaching the SDG 3 (Health)—Benchmarking to Best Performers".

_ 2018. "Cost of Reaching the SDG 4 (Education)—Benchmarking to Best Performers".

Sachs, Jeffrey (2012): "From Millennium Development Goals to Sustainable Development Goals".

Schmidt-Traub, G. (2015) "Investment Needs to Achieve the Sustainable Development Goals. Understanding the Billions and Trillions". Sustainable Development Solutions Network-A Global Initiative for the United Nations. Working Paper.

Schmidt-Traub, Guido, et al. "National baselines for the Sustainable Development Goals assessed in the SDG Index and Dashboards." Nature Geoscience 10.8 (2017): 547. http://dx.doi.org/10.1038/ngeo2985.

Sustainable Development Solutions Network (SDSN) and the Bertelsmann Stiftung (2018): "2018 SDG Index and Dashboards Report", available at: http://www.sdgindex.org/ .

UNDP and ASEAN Secretariat (2015): Report of the ASEAN Regional Assessment of MDG Achievement and Post-2015 Development Priorities.

World Bank, 2015, Water Supply and Sanitation in Indonesia: Turning Finance into Service for the Future.

_ 2016, The Costs of Meeting the 2030 Sustainable Development Goal Targets on Drinking Water, Sanitation, and Hygiene. 


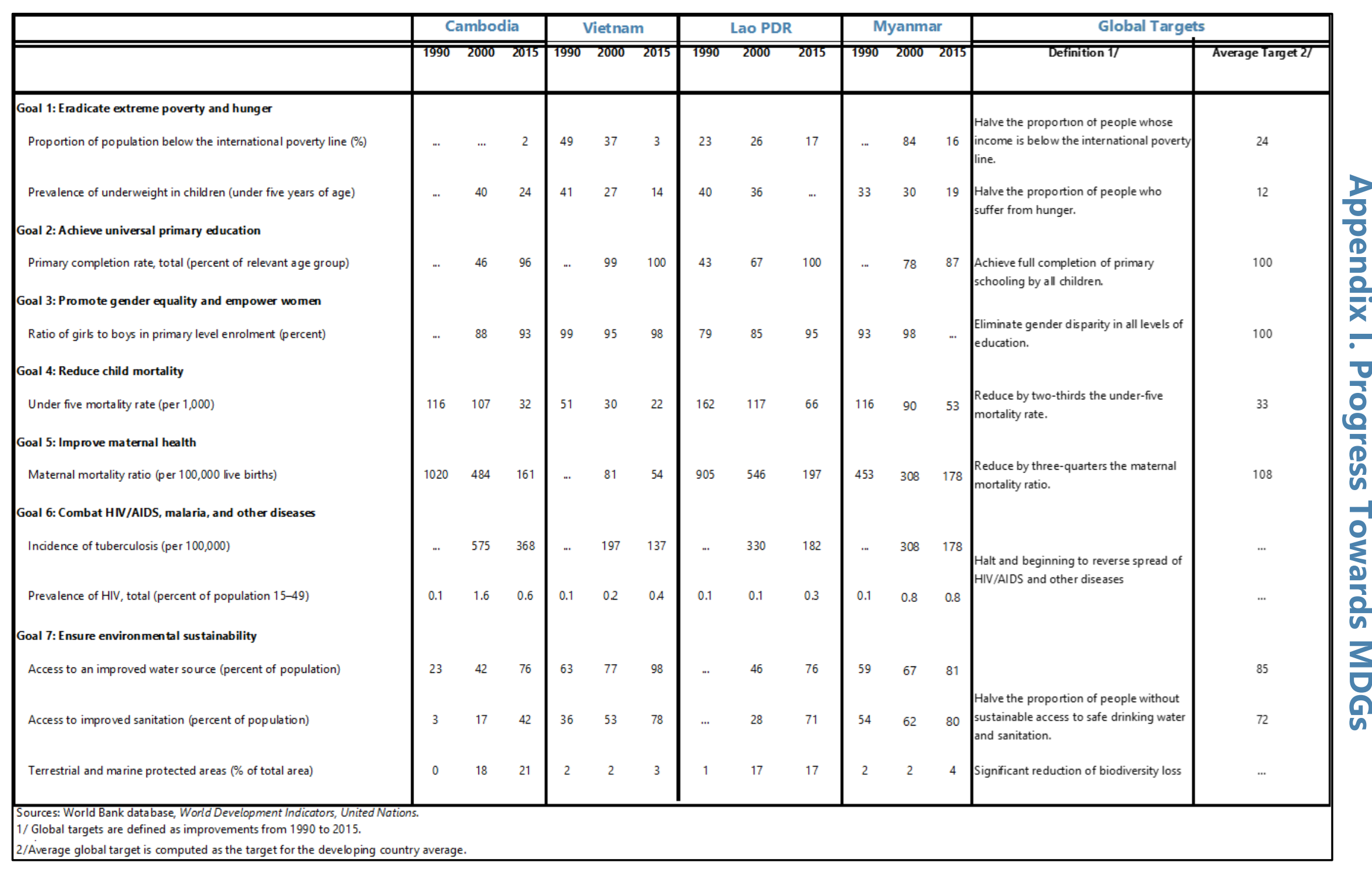




\section{Appendix II. Welfare Index Methodology ${ }^{1}$}

What is consumption equivalent welfare? This is a measure of economic utility or satisfaction derived from consumption. In line with economic theory, the welfare index assumes that welfare is proportional to the amount of consumption per capita that an economy can achieve or provide its citizens. The index then asks: for a consumer with some standard set of preferences, what factor or proportion of consumption in country A (say the US) would make him/her indifferent to living in country $A$ or in country $B$. This proportion is then a measure of the consumption equivalent welfare in country $B$ relative to country $A$.

What are the components of the index? In addition to consumption, the index includes other factors that affect consumption over the consumer's lifetime. The first is life expectancy - the longer you live the more years of consumption are achieved. The second is hours worked - the more hours worked for the level of consumption achieved the less welfare. The third is inequality; if the distributions of income and consumption are highly unequal, then there is a higher chance of being stuck at the low end of the distribution, and expected welfare is lower. Finally, higher greenhouse gas emissions entail greater environmental costs that are assumed to come out of consumption, and therefore reduce welfare. The approach assumes that the polluter internalizes the negative global externalities from greenhouse gas emissions through a tax on consumption. ${ }^{2}$

How are these elements put together in the index? The index is different from other measures of welfare in that it is not a simple average of indicators of development, like the SDG index (Sustainable Development Solutions Network and the Bertelsmann Stiftung, 2018) and the Human Development Index (UNDP, 2016). Instead it is derived from a consistent theoretical model that attempts to capture the way each of the components affect consumption equivalent welfare. The benefit of this approach is that it is a theoretically consistent way of looking at dimensions of economic welfare that are not captured by GDP per capita or other measures of economic success. The cost of this approach is that it only encompasses a limited number of development indicators, concentrating on the economic dimensions, and not covering other dimensions such as quality of life, peace and justice, gender equity and environmental quality that are included in the SDGs.

How do the indexes compare? The welfare index is highly correlated with the Global SDG index, with respect to ASEAN countries. The two indexes have a Pearson correlation coefficient of 0.71 and a rank order correlation of 0.87 . This implies that both indexes are measuring a similar underlying variable related to the level of development and to consumption equivalent welfare.

\footnotetext{
${ }^{1}$ For a technical discussion of the welfare index, see Bannister and Mourmouras (2017).

${ }^{2}$ An alternative modelling approach would be to account explicitly for the local damage from greenhouse gas emissions.
} 


\title{
Appendix III. Costing Methodology
}

\begin{abstract}
The costing exercise focuses on education, health, and selected areas of infrastructure (roads, electricity, and water). These are investment-type sectors that contribute to improving social, human, and physical capital. Governments typically play a decisive role in these sectors, with on average, about one-third of public budgets devoted to them. Furthermore, these sectors have synergies with many other SDGs, including reducing poverty and inequality. The exercise aims to provide an estimate of the costing of inputs needed to support good outcomes in these different sectors, independent of the form of financing which can come from governments, the private sector, or international aid.
\end{abstract}

Education. For each country, we estimate the cost of setting key parameters (teacher salaries, pupils per teachers, and share of non-compensation expenses) in 2030 equal to the median values observed today in good-performing countries (those that exceed 80 in the SDG education index). ${ }^{1}$ The estimations are done separately by income group using country projections for economic growth and demographics. The additional spending needs are the difference between the estimated cost and the current levels of expenditure, expressed in percent of 2030 GDP.

Health. We estimate for each country the cost of setting key parameters (medical personnel, doctors and other medical personnel per population, share of non-compensation expenses) in 2030 equal to the median values observed today in good-performing countries (those that exceed 70 in the SDG health index). The estimations are done separately by income group and consider country specific projections for economic growth and demographics. The additional spending needs are the difference between the estimated cost and the current levels of expenditure in percent of 2030 GDP.

Roads. Using regression analysis, for each country we estimate the additional kilometers of roads that will be needed to account for: i) projected changes in population and GDP per capita over 2016-2030, and ii) ensuring access for all (proxied by raising the Rural Access Index to 90 percent). ${ }^{2}$ The cost of the additional road network is estimated assuming a cost per kilometer (set at a minimum of $\$ 500,000$ ), dividing the expenditure by 12 years, and expressing the result as a share of 2030 GDP. To account for depreciation, we add five percent of the total cost of the additional kilometers.

Electricity. For each country, we estimate the cost of increasing electricity access to 100 percent of the projected population by 2030, assuming per capita consumption will increase as the projected

\footnotetext{
${ }^{1}$ The costing exercise is based on benchmarking sectoral inputs-levels and mix - that are consistent with relatively good development outcomes. Therefore, performance thresholds are set in order to have enough and diverse goodperforming peers in different income groups, in particular among LIDCs, allowing for a relatively robust benchmarking. These thresholds are 80 for education, 70 for health, 75 for roads and 100 for electricity and water.

2 Following Fay and Yepes (2003), we estimate a cross-section regression of 86 countries $\left(R D_{i}=C+\beta_{1} Y_{i}+\beta_{2} P D_{i}+\right.$ $\left.\beta_{3} R A I_{i}+\beta_{4} X_{i}+\varepsilon_{i}\right)$, where RD is road density, $\mathrm{Y}$ is GDP per capita, PD is the population density, RAl is the rural access index, and $X$ is a vector including the share of agriculture, share of manufacturing, and the degree of urbanization.
} 
increase in real GDP per capita. The cost of the additional consumption is estimated assuming a cost to generate and distribute energy of $\$ 2,250$ per kilowatt.

Water. We use the World Bank methodology, which estimates population in need of basic and improved access to water and sanitation (Hutton and Varughese, 2016). The unit costs are calibrated at the country level.

Country specific adjustments. We discussed case studies for Indonesia and Vietnam with country authorities and development partners to validate the methodology. Reflecting these discussions, we made adjustments to some parameters including higher electricity cost for Indonesia $(\$ 2,560$ per kilowatt), and higher cost per road ( $\$ 1$ million) and faster increase in per capita electricity consumption (8 percent per year) for Vietnam. In addition, we adopted higher benchmarks for Vietnam reflecting its relatively good SDG performance. Vietnam is benchmarked against a higher income group for education and health care and the threshold for the reference SDG health care index is increased to 80 . 


\section{Appendix IV. IMF's New Initiatives Under the 2030 Development Agenda}

In 2015, the IMF has committed to new initiatives as part of the 2030 Development Agenda to support countries in the areas of strengthening resource mobilization, building state capacity for infrastructure provision, pursuing economic and gender inclusion, addressing the challenges of climate change, and strengthening statistical reporting systems. The IMF's work agenda on governance under the enhanced framework recently approved by the Board should also support countries' efforts to pursue the SDGs.

\section{A. Strengthening Tax Capacity}

To better assist countries to strengthen their revenue generating capacity, in 2015 the IMF launched a pilot initiative to further integrate domestic revenue (DRM) and international taxation (IT) issues in surveillance. So far, [50] pilots on DRM and [24] pilots on IT have been completed, including Philippines, Malaysia, and Indonesia among the ASEAN countries. The IMF has also developed various tools, including

- Tax Administration Diagnostic Assessment Tool (TADAT) ${ }^{\mathbf{1}}$ to assess key functions, processes and institutions of tax administration systems. Assessments using TADAT were undertaken in Malaysia (2015), Philippines (2015), and Vietnam (2016).

- Revenue Administration Gap Analysis Program (RA-GAP) to assess gaps in value-added tax (VAT) and corporate income tax (CIT). Analysis of VAT gaps have been conducted in the Philippines (2012, 2014, 2016), Thailand (2015) and is ongoing in Indonesia.

- $\quad$ Revenue Administration Fiscal Information Tool (RA-FIT/ISORA), a survey-based dataset on revenue administration practices. The most recent survey dataset (2016) provides information for all ASEAN countries.

- $\quad$ Tax Policy Assessment Framework (TPAF) ${ }^{2}$ to assess tax policy. Under the framework a VAT module has been developed and work on modules for the personal income tax (PIT) and fiscal regimes for extractive industries is underway.

In the context of the Platform for Collaboration on Tax (PCT), the IMF and its partners have developed several toolkits to support countries with international tax issues, including the "Efficient and Effective use of Tax Incentives for Investment in low Income Countries" and "Comparables for Transfer Pricing."

\footnotetext{
${ }^{1}$ The tool has been developed in collaboration with other partners, including the European Commission, Germany, Japan, Netherlands, Norway, Switzerland, United Kingdom, and the World Bank.

2 The framework has been developed in collaboration with the World Bank.
} 
Forthcoming tools focus on: (i) offshore indirect transfers of assets; (ii) tax treaty negotiation; and (iii) transfer pricing.

Medium Term-Revenue Strategies (MTRS) — In collaboration with PCT partners, the IMF has developed the MTRS approach to tax system reform, which brings financing and expenditure together to support the SDGs. Discussions on a MTRS are underway with Myanmar, a country receiving intensive TA under the IMF Revenue Mobilization Trust Fund (RMTF), to help the transition of the country's tax system reform efforts into MTRS approach. MTRS for Indonesia and Thailand have been completed.

\section{B. Building State Capacity for Infrastructure Provision}

The Fund's Infrastructure Policy Support Initiative (IPSI) helps to identify macro-fiscal implications of scaling up spending and to build institutional capacity. The IPSI tools include

- Public Investment Management Assessment (PIMA) to assess the quality of public investment practices and help countries strengthen the efficiency and effectiveness of public investment. Technical assistance on PIMA was provided to six countries in East Asia, of which two are ASEAN countries, Malaysia in 2017 and Thailand in 2016. PIMA missions to Indonesia, Philippines and Vietnam are planned in 2018-19.

- PPP Fiscal Risk Assessment Model (P-FRAM) to assess the potential fiscal costs and risks arising from PPPs. Technical assistance on P-FRAM was provided to Cambodia in 2017 and 2018. A regional seminar on fiscal risk management was organized in 2018 with participants from Indonesia, Lao PDR, Malaysia, Myanmar, Philippines, Thailand, and Vietnam.

- Debt-Investment-Growth (DIG) model to analyze macroeconomic and fiscal implications of public investment scaling-up in a general equilibrium framework. Its extension to account for the natural resource sector (DIGNAR) considers commodity price volatility and government resource revenue management. The DIG/DIGNAR has been applied to Cambodia (2016), Myanmar (2014), Thailand (2017), and Vietnam (2017).

- Debt Sustainability Assessments (DSA) to assess the sustainability of fiscal policy. Applied to all countries as part of the Fund's annual surveillance.

- Medium-Term Debt Management Strategy (MTDS) to optimize the government's debt portfolio. Technical assistance was provided to Cambodia for its 2019-2023 MTDS, Indonesia for its 2013-17 MTDS, and to Vietnam for its 2015-2020 MTDS.

\section{Pursuing Economic and Gender Inclusion}

To support surveillance and program discussions, the IMF has stepped up efforts to operationalize its work on inclusive growth. As part of a pilot initiative on inequality and gender that started in 2015, income and gender inequality issues have been included in policy discussions in 
countries where these issues are seen as macroeconomically relevant. Once the pilots are completed, the IMF plans to incorporate the analysis of income and gender inequality issues into broader country work with the coverage calibrated to the degree of macroeconomic significance. Moreover, the IMF compiles gender-specific data on financial access to enable countries to better understand the impact of their economic policies on women. It is also helping boost female labor market participation, providing training on gender budgeting, publicizing best practices, and empowering female government officials through training.

Pilot studies on inequality and gender have examined a wide range of issues in the ASEAN. On income inequality, the pilot studies focus on issues such as the growth-inequality tradeoffs in reform packages and options to increase the traction of reforms from both growth and distributional perspectives; regional income inequality; and comparative analysis of inequality and poverty outcomes. Studies were undertaken for Myanmar (2016) and Singapore (2017) and are ongoing for Cambodia and Lao PDR. On gender, the pilots have examined potential barriers to female labor force participation in countries at various levels of development and the impact of specific reforms and policies on gender inequality. Studies on gender for Lao PDR and Vietnam are ongoing.

With the support of the UK's Department for International Development (DFID), staff has developed an analytical framework to study distributional impacts of reform packages and the transmission channels. The framework can be easily customized to countries' macroeconomic features and micro characteristics and has been applied to inform policy discussions in about 15 countries at all levels of development. IMF has also developed a user-friendly toolkit based on this framework. Furthermore, the model has been extended to analyze the impact of reforms on female labor force participation and wage gap.

The IMF has also stepped up its work on the role of fiscal policy to address gender inequality, the basic idea behind gender budgeting. It has conducted a study focusing on gender budgeting practices in the G7 (IMF, 2017b) and has recently published a book that takes stock of gender budgeting practices in 80 countries, including in ASEAN countries, and discusses gender budgeting in 23 countries with noteworthy effort (Kolovick, 2018). The main lessons suggest that advanced countries could use individual taxation, increase parental leave and child and elderly care, and encourage equal employment opportunities/wages to boost female labor force participation. In developing countries, gender budgeting efforts should focus on education, health, and infrastructure spending to reduce gender inequality. The IMF has also provided TA on gender budgeting in the context of public financial management, including in Cambodia.

\section{Addressing the challenge of Climate Change}

The IMF plays a significant role in supporting countries to adopt policies that reduce the macroeconomic risks posed by climate change and help build resilience and adaptation (IMF 2015d). Ahead of the COP21 Paris Agreement in 2015, the IMF committed to: (i) provide technical assistance and training in fuel tax design and energy price reform; (ii) collaborate with other international organizations to promote policy dialogue among key stakeholders, emphasizing the 
benefits of carbon pricing as one component of an effective tax structure; (iii) integrate natural disaster risks and preparedness strategies in macroeconomic forecasts and debt sustainability analyses; (iv) help countries incorporate adaptation strategies in medium-term fiscal frameworks; and (v) work closely with other institutions to encourage consistent climate-related disclosures, prudential requirements, and stress testing for the financial sector.

Since 2015, the IMF has operationalized its commitments under the energy/climate initiative. The IMF has been helping member countries implement their mitigation pledges for the Paris Agreement, and has strengthened dialogue on climate resilience and energy price reform in surveillance. The centerpiece of the climate/energy initiative is the development of spreadsheet tools for estimating carbon prices needed to meet mitigation commitments, their broader environmental, fiscal, and economic impacts, and tradeoffs with other (fiscal and regulatory) instruments. The IMF works with countries on environmental tax reform and efficient energy pricing to minimize the effects of climate change. To inform country strategies on building resilience and preparedness, the IMF in collaboration with the World Bank has launched a joint Climate Change Policy Assessment (CCPA) providing country-specific frameworks assessing preparedness to climate change, climate mitigation and adaptation plans, and risk management strategies. In addition, the IMF's recently revamped debt sustainability framework has a new feature that incorporates natural disaster costs.

\section{E. Strengthening Economic Institutions for Good Governance}

\section{While the IMF has long recognized the importance of good governance as a key pillar for economic development, it has recently adopted a more systematic and structured approach to it. In April 2018, building on the 1997 guidance note on governance, the IMF adopted a new framework for Enhanced Fund engagement to better assess corruption vulnerabilities (2018b). The new framework covers: (i) fiscal governance; (ii) financial sector oversight; (iii) central bank governance; (iv) market regulation; (v) rule of law; (vi) anti-money laundering and combating the financial terrorism; and (vii) corruption.}

The new framework defines the IMF work agenda on governance. It guides the Fund assessment of the macroeconomic implications of governance issues and corruption vulnerabilities taking into account the applicable standards for surveillance and the use of Fund resources. It helps inform policy advice and institutional capacity development support to member countries. It also focuses on measures designed to prevent the private actors from offering bribes or providing services that facilitate concealment of corruption proceeds. Assessments for a few IMF member countries are being prepared and will be discussed with country authorities. Assessments for the remaining countries will also take place in due course.

\section{F. Strengthening Statistical Reporting Systems}

The IMF continues to assist member countries in expanding their statistical capacity, with a strong emphasis on promoting data dissemination and transparency. The enhanced General 
Data Dissemination System (e-GDDS), approved by the IMF Executive Board in May 2015, aims to help countries produce a fully operational National Summary Data Page (NSDP). The NSDP is a national data portal that serves as a one-stop vehicle for publishing essential macroeconomic data in both human and machine-readable formats. It provides national policymakers and a broad range of domestic and international stakeholders, including investors and rating agencies, with easy access to information critical for monitoring economic conditions and policies. Making this information simultaneously available to all users brings greater data transparency ${ }^{3}$.

\section{The Fund's Data Standard Initiative is currently ongoing in four ASEAN countries: Cambodia,} Lao PDR, Myanmar, and Vietnam. Cambodia implemented the e-GDDS in May 2018 with the Fund's technical assistance in February 2018. Cambodia's NSDP is hosted by the National Bank of Cambodia on its website, which is also accessible through the IMF's Dissemination Standards Bulletin Board. In June 2018, a technical assistance mission was fielded to Lao PDR to support the authorities' efforts to implement the e-GDDS. The mission assisted the authorities in preparing a National Summary Data Page. Technical assistance missions to Myanmar and Vietnam are planned for early 2019.

\footnotetext{
${ }^{3}$ All NSDPs are accessible through the IMF's Dissemination Standards Bulletin Board at: $\underline{\text { https://dsbb.imf.org/ }}$
} 